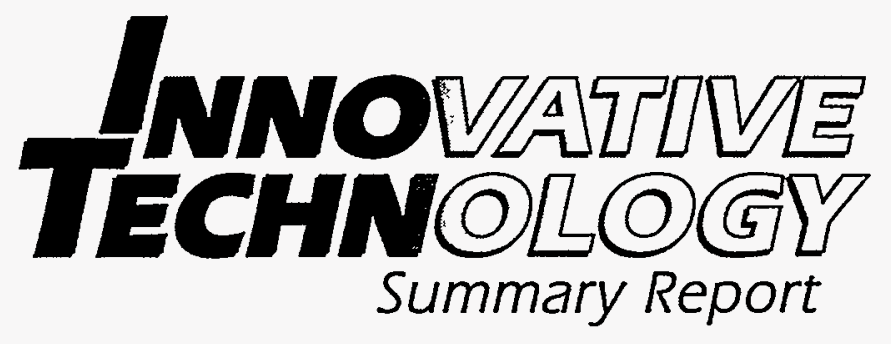

\title{
Wireless Remote Radiation Monitoring System (WRRMS)
} OST Reference \#2104

Deactivation and Decommissioning Focus Area

MASTER

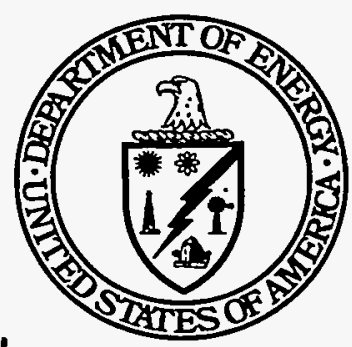

DSTRISUTION OF THIS DOCUMENT is UNHIS Demonstrated at Hanford Site Richland, Washington 


\section{DISCLAIMER}

This report was prepared as an account of work sponsored by an agency of the United States Government. Neither the United States Government nor any agency thereof, nor any of their employees, make any warranty, express or implied, or assumes any legal liability or responsibility for the accuracy, completeness, or usefulness of any information, apparatus, product, or process disclosed, or represents that its use would not infringe privately owned rights. Reference herein to any specific commercial product, process, or service by trade name, trademark, manufacturer, or otherwise does not necessarily constitute or imply its endorsement, recommendation, or favoring by the United States Government or any agency thereof. The views and opinions of authors expressed herein do not necessarily state or reflect those of the United States Government or any agency thereof. 


\section{DISCLAIMER}

Portions of this document may be illegible in electronic image products. Images are produced from the best available original document. 


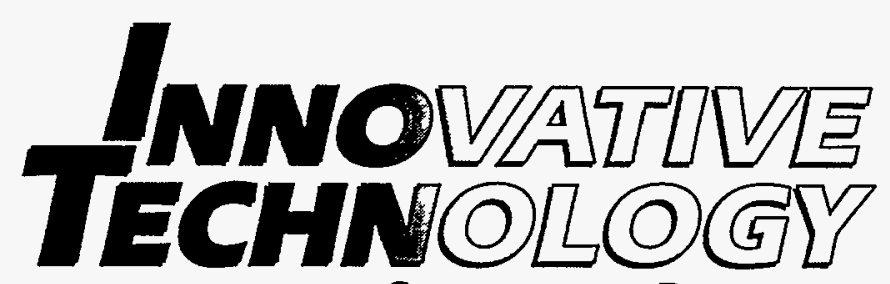

Summary Report

\section{Purpose of this document}

Innovative Technology Summary Reports are designed to provide potential users with the information they need to quickly determine if a technology would apply to a particular environmental management problem. They are also designed for readers who may recommend that a technology be considered by prospective users.

Each report describes a technology, system, or process that has been developed and tested with funding from DOE's Office of Science and Technology (OST). A report presents the full range of problems that a technology, system, or process will address and its advantages to the DOE cleanup in terms of system performance, cost, and cleanup effectiveness. Most reports include comparisons to baseline technologies as well as other competing technologies. Information about commercial availability and technology readiness for implementation is also included. Innovative Technology Summary Reports are intended to provide summary information. References for more detailed information are provided in an appendix.

Efforts have been made to provide key data describing the performance, cost, and regulatory acceptance of the technology. If this information was not available at the time of publication, the omission is noted.

All published Innovative Technology Summary Reports are available on the OST Web site at http://OST.em.doe.gov under "Publications." 


\section{TABLE OF CONTENTS}

1 SUMMARY

page 1

2 TECHNOLOGY DESCRIPTION

page 5

3 PERFORMANCE

page 8

4 TECHNOLOGY APPLICABILITY AND ALTERNATIVE TECHNOLOGIES

$5 \cos T$

6 REGULATORY AND POLICY ISSUES

7 LESSONS LEARNED

\section{APPENDICES}

A References

B Cost Summary

B N-Basin Report

B Acronyms and Abbreviations 


\section{SECTION 1}

\section{SUMMARY}

The Science Application International Corporation (SAIC) RadStar ${ }^{\text {TM }}$ wireless remote radiation monitoring system (WRRMS) is designed to provide real-time monitoring of the radiation dose to workers as they perform work in radiologically contaminated areas. WRRMS can also monitor dose rates in a room or area. The system uses radio-frequency communications to transmit dose readings from the wireless dosimeters worn by workers to a remote monitoring station that can be located out of the contaminated area. Each base station can monitor up to 16 workers simultaneously. The WRRMS can be preset to trigger both audible and visual alarms at certain dose rates. The alarms are provided to the worker as well as the base station operator. This system is particularly useful when workers are wearing personal protective clothing or respirators that make visual observation of their self-reading dosimeters (SRDs), which are typically used to monitor workers, more difficult. The base station is an IBM-compatible personal computer that updates and records information on individual workers every ten seconds. Although the equipment costs for this improved technology are higher than the SRDs (amortized at $\$ 2.54 / \mathrm{hr}$ versus $\$ 1.02 / \mathrm{hr}$ ), total operational costs are actually less ( $\$ 639 /$ day versus $\$ 851 /$ day). This is because the WRRMS requires fewer workers to be in the contaminated zone than the traditional (baseline) technology. There are also intangible benefits associated with improved worker safety and as low as reasonably achievable (ALARA) principles, making the WRRMS an attractive alternative to the baseline technology. The baseline technology measures only integrated dose and requires workers to check their own dosimeters manually during the task.

\section{Technology Summary}

The RadStar ${ }^{T M 1}$ wireless remote radiation monitoring system (WRRMS), is a health and safety technology that can provide real-time monitoring of personnel dose and area exposure rates to beta and gamma radiation. WRRMS, developed by Science Applications International Corporation (SAIC), consists of alarming electronic transceiver dosimeters worn by workers, a portable monitor system that utilizes radio-frequency communications, an IBM-compatible personal computer and transceiver base station, and a dosimeter reader for calibrations and setting alarms. The computer collects, displays, and records data from individual workers. The computer also updates the dose or exposure rate of each worker or an area every eight to ten seconds, allowing proactive decisions about whether to modify worker activity to avoid situations in which over-exposure to radiation could occur. The WRRMS can monitor up to 16 workers per base station.

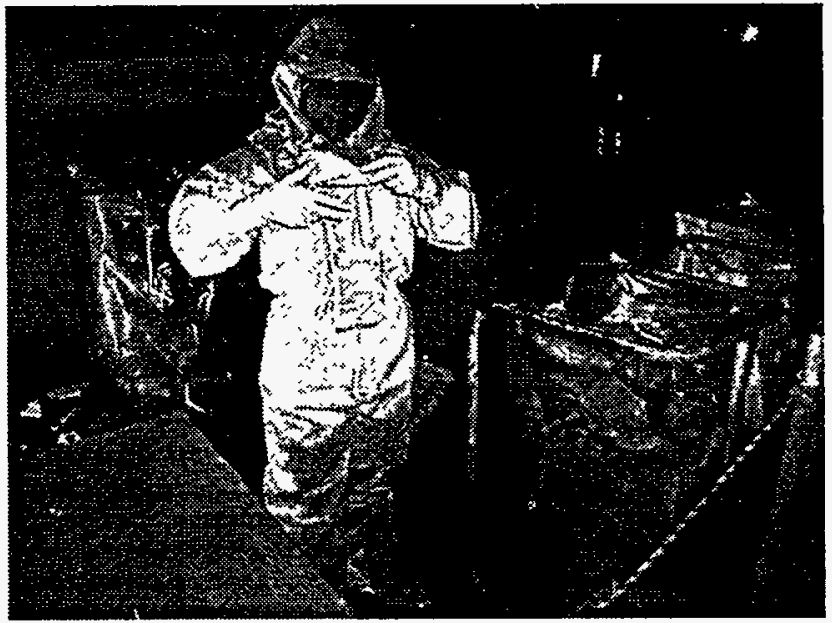

\section{Problem Addressed}

The U.S. Department of Energy's (DOE's) nuclear facility decontamination and decommissioning (D\&D) program and deactivation activities requires the expeditious and cost-effective D\&D of buildings. Simultaneously, the health and safety of personnel involved in the D\&D activities is of primary concern. Often, D\&D workers must perform duties in contamination zones including high radiation areas. Typically, personnel exposure levels are monitored using pencil dosimeters (self-reading dosimeters [SRDs]), which are read by the wearer or by a radiological control technician (RCT) after personnel leave the contamination zone. To maintain as low as reasonably

${ }^{1} \operatorname{RadStar}^{\top \mathrm{M}}$ is a trademark of Science Applications International Corporation, San Diego, California. 
achievable (ALARA) exposure principles and to enhance the health and safety of the workers, DOE was searching for a cost-effective alternative to the pencil dosimeter.

\section{Features and Configuration}

- The system provides real-time monitoring and data read-out for gamma and beta radiation.

- In normal operation mode, a signal from each dosimeter is received every 10 seconds, processed, and recorded by the RadStar ${ }^{\mathrm{M} M}$ software on the computer. The information from one individual is automatically updated and recorded by the computer in an appropriate dosimeter file.

- The wearable monitor is lightweight, weighing less than $400 \mathrm{~g}(0.9 \mathrm{lb})$, and worn in the front chest area (see Figure 4 in Section 2).

- Electronic dosimeters on this system can be preset to alarm at a threshold point to ensure workers are not over exposed to radiation. If a person's dosimeter exceeds the alarm set point dose, the system will automatically activate a light-emitting diode or an audible alarm (approximately 100 decibels) warning both the person and the base station.

- The person manning the supervisory station can manually alarm another person working in the radiation area.

- The wireless system can transmit straight-line signals over $3,050 \mathrm{~m}(10,000 \mathrm{ft})$.

- Signal transmission can be preset ( 1 to 300 minutes) to cease for a low battery, which is dependent upon required dose rate data and transmitting intervals. After the preset low-battery signal transmission is tripped, the electronic dosimeter stops sending a signal and becomes a local dosimeter.

\section{Potential Markets/Applicability}

The WRRMS can be used at any facility in which the level of beta or gamma radiation must be measured, or worker exposure rates must monitored. This includes not only DOE sites, but also U.S. Environmental Protection Agency and U.S. Nuclear Regulatory Commission sites. The WRRMS is particularly useful when work must be performed in high radiation areas or when personal protective clothing or respirators must be worn, which restricts the worker from reading the SRDs properly, especially in areas with low lighting.

\section{Advantages of the Improved Technology}

- $\quad$ Provides supervisors with the ability to observe the real-time worker dose and area exposure rate.

- Can establish accumulated dose databases for individual workers.

- $\quad$ Has an alarm system that prevents potential over exposure.

- Can monitor up to 10 individual employees with a different alarm set point for each.

- The system base station computer can monitor up to 16 individual employees with the same alarm set point. 
The following table summarizes a comparison of the improved technology, the RadStar ${ }^{\mathrm{TM}}$ WRRMS, and the baseline, self-reading pencil dosimeters:

\begin{tabular}{|l|l|}
\hline \multicolumn{1}{|c|}{ Category } & \multicolumn{1}{|c|}{ Comments } \\
\hline Cost & $\begin{array}{l}\text { Equipment costs are higher than the baseline (amortized at } \$ 2.54 / \mathrm{hr} \text { versus } \\
\$ 1.02 / \mathrm{hr}), \text { but the labor costs of one RCT can be eliminated, thereby reducing } \\
\text { overall operational costs (\$639/day versus costs of } \$ 851 / \text { day) for the improved } \\
\text { and baseline technologies, respectively. }\end{array}$ \\
\hline Performance & Better than the baseline; can provide real-time monitoring system. \\
\hline Implementation & $\begin{array}{l}\text { No special site services required for implementing this, except a calibration } \\
\text { facility for routine calibration. }\end{array}$ \\
\hline Secondary Waste Generation & Does not generate secondary waste. \\
\hline ALARASafety & $\begin{array}{l}\text { Compared to the baseline technology, use of this tool increases the benefit of } \\
\text { ALARA and safety consideration, significantly reducing the likelihood of a } \\
\text { worker being over exposed to radiation. Although this is an intangible benefit, } \\
\text { there is a reduction of dose. For this demonstration the dose savings was } \\
\text { estimated at over } \$ 24,000, \text { achieved by eliminating the need for one RCT } \\
\text { entering the radiological zone. }\end{array}$ \\
\hline Ease of use & \begin{tabular}{l} 
Easy to use; short learning curve to operate the system. \\
\hline
\end{tabular}
\end{tabular}

\section{Operator Concerns}

The life of the battery used for operation of the dosimeter and transmission signals is limited to approximately 8 hours. Additionally, the main transmission system can experience interference in areas with structural obstructions. However, interference can be minimized by using the wireless transmission components of the dosimeters as repeaters to transmit around interferences, or by adding an antenna. Instead of batteries, an alternating-current adapter can be used for repeaters and for dosimeters used for area monitoring.

\section{Skills/Training}

Required instruction for D\&D workers and RCTs in using the dosimeters was minimal (approximately 5 minutes of instruction). The RCT attending the base station needed basic knowledge of personal computer operations and some familiarity with the software. Five hours of on-the-job training were completed to gain this familiarity.

\section{Demonstration Summary}

This report covers the period September through December 1997 when the RadStar ${ }^{\mathrm{TM}}$ WRRMS with gamma probes was demonstrated at the DOE's Hanford Site C Reactor and was compared to SRDs, and in July 1998 with a beta probe and gamma probe at the $\mathrm{N}$ Reactor where Eberline RO-2 ion chambers were used as the baseline. This was the first demonstration of this technology with a beta probe at a DOE facility.

\section{Demonstration Site Description}

At its former weapons production sites, the DOE is conducting an evaluation of improved technologies that might prove valuable for facility D\&D. As part of the Hanford Site Large-Scale Demonstration and Deployment Project (LSDDP) at the C Reactor Interim Safe Storage (ISS) Project, at least 20 improved technologies will be demonstrated and assessed against baseline technologies currently in use. DOE's Office of Science \& Technology (OST)/Deactivation and Decommissioning Focus Area, in collaboration with the Environmental Restoration Program, is undertaking a major effort to demonstrate improved and improved technologies at its sites nationwide. If 
successfully demonstrated at the Hanford Site, these improved technologies could be implemented at other DOE sites and similar government or commercial facilities.

To support the C Reactor ISS Project, which is managed by DOE's Richland Operations (DOE-RL) at the Hanford Site in Richland, Washington, workers must often perform duties in contaminated or limited access areas, or in elevated radiation areas. Additionally, workers are frequently required to wear personal protective clothing or equipment that may inhibit the worker's ability to read his/her SFD properly. These conditions may present the potential for a radiation over-exposure situation. Since worker safety is of primary concern at DOE facilities, monitoring the workers' accumulated dose and area exposure rates are a vital component to ensuring worker safety. The demonstration of the WRRMS at the $C$ Reactor was an effort to identify more effective alternatives to the SRD for gamma monitoring. Additionally, at the N Reactor deactivation project, dosages in the area around the spent fuel storage basin needed to be measured as the water was being removed. The WRRMS was used to monitor beta and gamma radiation.

\section{Regulatory Issues}

The RadStar ${ }^{T M}$ system is a wireless remote radiation monitoring system used for monitoring the personnel dose or area exposure rate. It meets Federal Communications Commission Part 15 regulations, and there are no special regulatory permits required for its operation and use. This system can be used in daily operations within the requirements of 10 Code of Federal Regulations (CFR), Parts 20 and 835, and proposed Part 834 for radiological protection of workers and the environment, and Occupational Safety and Health Administration (OSHA) guidelines (29 CFR).

\section{Technology Availability}

The RadStar ${ }^{\text {TM }}$ WRRMS is a patented product that is commercially available.

\section{Technology Limitations/Needs for Future Development}

The transmission signal has some limitations and should be tested when being used in areas with obstructions and thick concrete walls. Antennas could be installed e.g., a long-range, highly directional shortwave Yagi antenna) to increase radio frequency signal strength. This would avoid the necessity to assign PD-4 dosimeters as repeaters in areas with obstructions.

\section{Contacts}

\section{Management}

John Duda, FETC, (304) 285-4217

Jeff Bruggeman, DOE-RL, (509) 376-7121

Shannon Saget, DOE-RL, (509) 372-4029

Technical

Stephen Pulsford, BHI, (509) 375-4640

Gregory Gervais, USACE, (206) 764-6837

\section{Licensing Information}

Dana Eamons, SAIC, (619) 646-9830

\section{Others}

All published Innovative Technology Summary Reports are available at Internet web site http://em-50.em.doe.gov. The Technology Management System, also available through the EM50 web site, provides information about Office of Science and Technology (OST) programs, technologies, and problems. The OST reference \# for Wireless Remote Radiation Monitoring System is 2104. 


\section{TECHNOLOGY DESCRIPTION}

\section{Overall Technology Definition}

The WRRMS is a series of electronic radio transmission dosimeters, transceiver base, monitor, and a personal computer that measures and displays the dose or exposure rates remotely while D\&D workers perform work activities. From the supervisory station, 16 workers can be monitored simultaneously. The real-time data can be used to detect potential problems instantaneously and adjust work activities accordingly to protect worker safety and ensure optimal worker productivity.

The RadStar'M WRRMS has the following components and features:

\section{Components}

- A host personal computer that monitors and records the information collected and transmitted by the radio transceiver electronic dosimeters and radio transceiver base using RadStar ${ }^{\mathrm{TM}}$ software.

- Model PD-4 and Model PDE-4 radio transceiver alarming gamma electronic dosimeters, each contained in a small plastic case to enclose the electronics and wireless radio components, gamma radiation detector, and a 9-volt non-rechargeable alkaline battery, which is used as an area dosimeter or is worn by the personnel. As an option, a probe with a beta window can be added to the PDE-4 units. The PD-4 units can also be adjusted to be used as a radio signal repeater when it is necessary to transmit the information around obstacles. This function can be achieved simply by adjusting the switch provided on the PD-4 unit from one position to the other.

- A Model PDX-4 transceiver base station, which is connected to the computer and receives the data and information from each dosimeter remotely and feeds it to the computer. In normal operation mode, a signal from each dosimeter is received every 10 seconds, processed, and recorded by the RadStar ${ }^{\mathrm{TM}}$ software on the computer. The information from one individual is automatically updated and recorded by the computer in an appropriate dosimeter file.

- A Model PDR-1 dosimeter reader, which is connected to the computer via an RS-232 connection that can access the PD-4's erasable programmable read-only memory storage area. This unit can read the dosimeters, adjust the calibration factor, set alarm levels, change the transmission interval, and will reset these items after use. Only alarm levels and the transmission interval on PD-4s can be changed via radio command using the personal computer; therefore, the PDR-1 is required during calibrations $(400 \mathrm{~kg})[0.9 \mathrm{lb}]$ and for configuring communication parameters.

\section{Features}

- The wearable monitor weighs less than $400 \mathrm{~g}(0.9 \mathrm{lb})$. The detector in this electronic dosimeter is an energycompensated Geiger-Mueller (GM) tube, which has a range of 10 milli-Roentgen (mR) to 999 Roentgen cumulative dose.

- Each electronic dosimeter on this system can be preset to alarm on an alarm set point.

- The unit accommodates an optional beta detector to measure beta dose and exposure rate.

Figure 1 shows the RadStar ${ }^{7 M}$ system components, and Figure 2 shows a schematic diagram of a typical RadStar $^{\mathrm{TM}}$ system configuration at work. Figure 3 shows a schematic diagram of the RadStar ${ }^{\mathrm{TM}}$ system configuration when a PD- 4 or multiple PD- 4 units are used to perform as repeaters. Figure 4 shows a PD-4 transceiver in actual use as a personal dosimeter. 

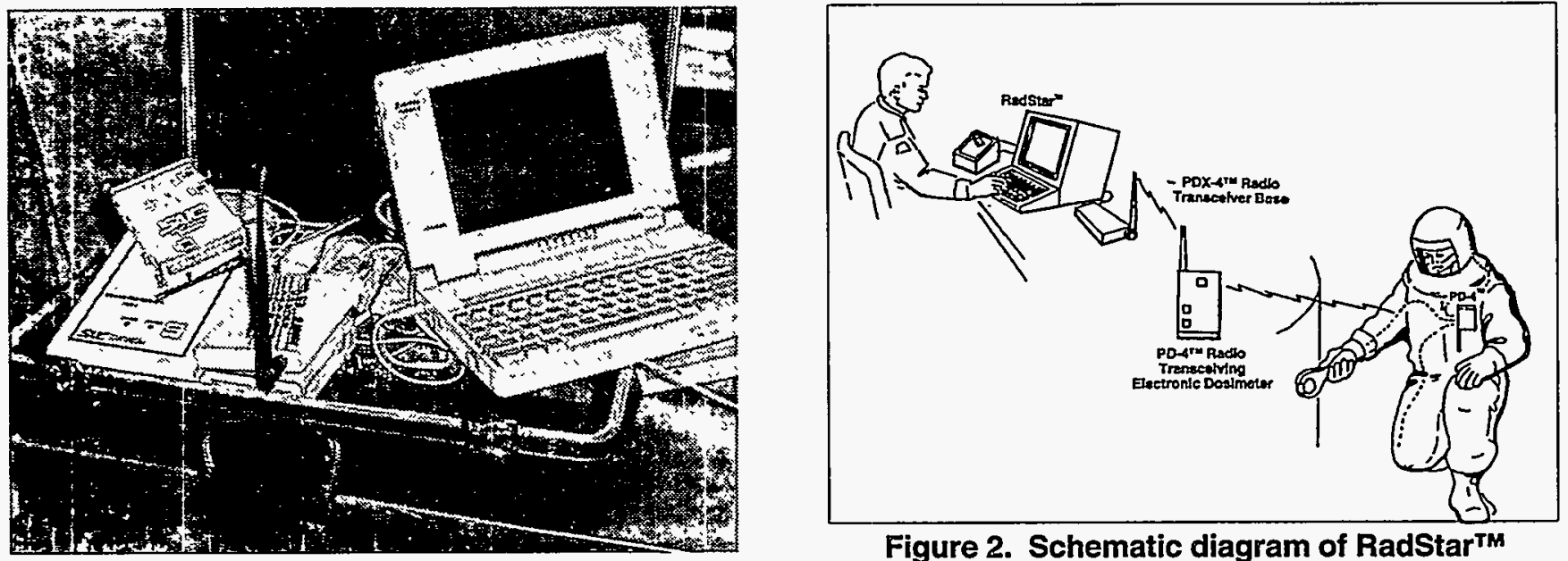

Figure 2. Schematic diagram of RadStar ${ }^{\mathrm{TM}}$ system configuration.

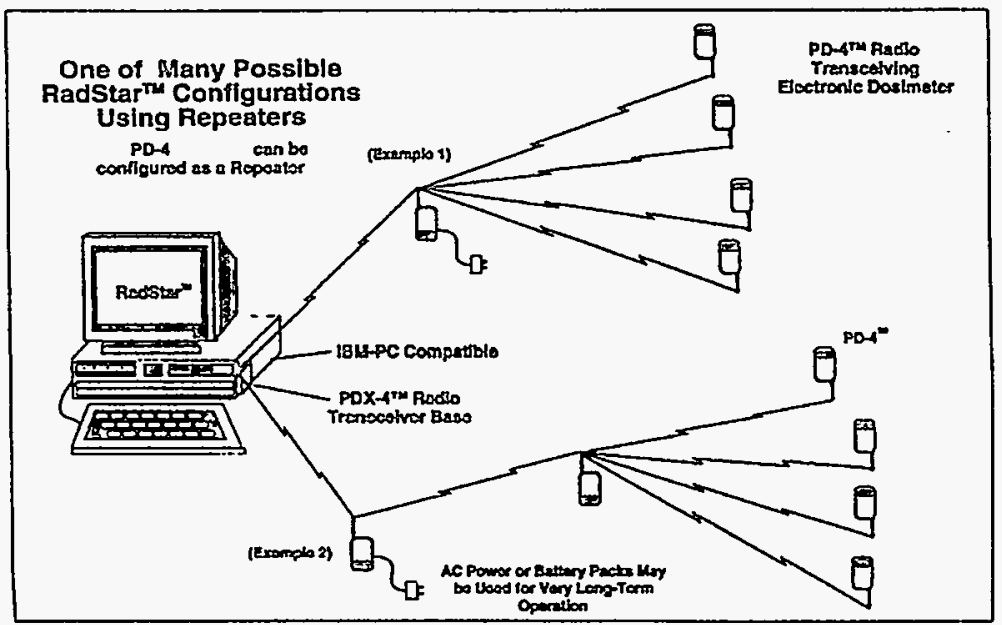

Figure 3. Schematic diagram of the RadStar'm system, PD-4 repeater configuration.

Sixteen workers can be monitored simultaneously by the supenisory station (base station). Additional groups of 16 workers each can be

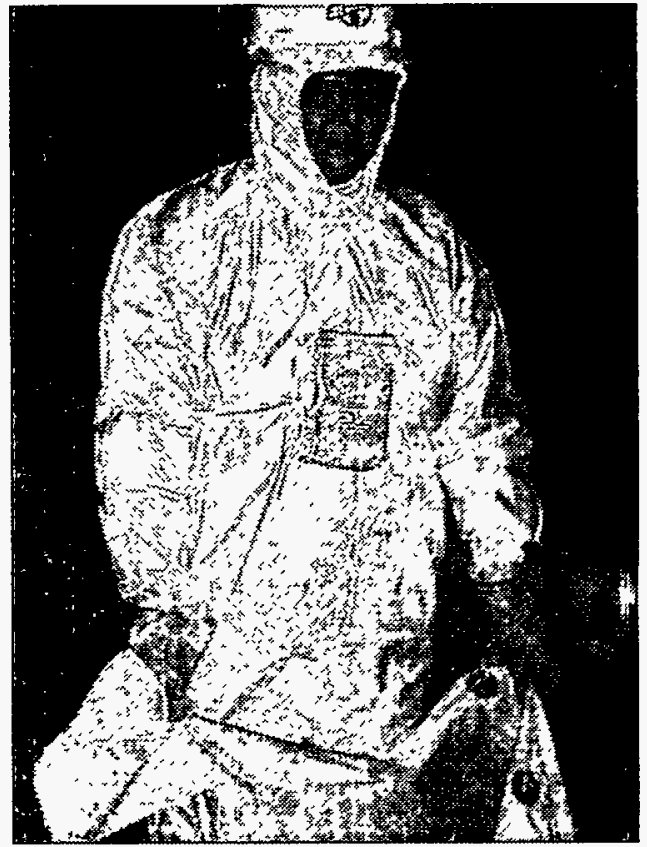

Figure 4. PD-4 as worn by personnel. accommodated by installing extremity cables, up to a maximum of four cables. The additional dosimeter could be used for area monitoring with cables, not wireless. In normal operation mode, a signal from each dosimeter is received every 10 seconds, processed, and recorded by the $\operatorname{RadStar}^{\mathrm{TM}}$ software on the computer. The information from one individual is automatically updated and recorded by the computer in the appropriate dosimeter file. If a person's dosimeter exceeds the alarm set point dose, the system will automatically activate the light-emitting diode or an audible alarm (approximately 85 decibels), warning both personnel and supervisor. In addition, the person manning the supervisory station can send a manual alarm another person working in the radiation area. After receiving the warning, the worker can withdraw from the work area and consult with the supervisor.

The RadStar ${ }^{\mathrm{MM}}$ WRRMS has wireless capability with signals that can be transmitted over $3,050 \mathrm{~m}(10,000 \mathrm{ft})$ with unobstructed view. The system meets the requirements of Federal Communications Commission Part 15 regulations and does not require licensing. 


\section{TECHNOLOGY DESCRIPTION}

The electronic dosimeters, PD-4s, are battery-operated, and the 9-volt battery used operates the dosimeter for 8 continuous hours transmitting every 10 seconds. Signal transmissions can be preset ( 1 to 300 minutes) to cease for low battery, which is dependent upon required dose rate data and transmitting intervals. After the preset low-battery signal transmission is triggered, the electronic dosimeter stops sending a signal and becomes a local dosimeter. An alternating-current adapter can be used instead of the battery. This is especially advantageous when using a dosimeter for area monitoring or as a repeater.

Data collected with RadStar ${ }^{7 M}$ system can easily be downloaded and manipulated, and operation requires basic computer skills.

\section{System Operation}

For the purposes of the demonstration at the $C$ Reactor, the system was set up and operated as follows:

- $\quad$ Start the computer and run the RadStar ${ }^{T M}$ software

- Check the computer and software setting for operation

- $\quad$ Connect the transceiver base station (PDX-4 unit) to the computer through a communications port using an RS-232 serial connection cable

- Using a Model PDR-1 dosimeter reader, read and reset the dosimeters

- Assign each transceiver dosimeter to personnel or to an area to be monitored by the sottware

- Set up the alarm setting parameters for each transceiver dosimeter (each person or each area)

- Attach the transceiver dosimeters to the personnel using the carrying case provided (see Figure 4 showing a unit, without a beta probe, in actual use)

- Check to see that the dosimeters are operational and produce reasonable results

- Save the setting and the configuration for the monitoring occurring at the time

- Start the system when the worker enters the radiological zone or the dosimeters are installed in an area

- Save the data onto the hard disk of the personal computer or on a floppy diskette

- Stop the software at the end of the monitoring session. 


\section{SECTION 3}

\section{PERFORMANCE}

\section{Demonstration Plan}

The demonstration was conducted at the DOE's Hanford Site. The purpose of the demonstration program is to demonstrate and document performance data, safety information, and costs for improved technologies that can aid in deactivating/decommissioning nuclear units and placing $C$ Reactor into an interim storage mode for up to 75 years (or until the final disposal of the reactor's core is completed and in deactivation) and can also be used for other decommissioning activities in the DOE complex. The C Reactor ISS objectives include placing the reactor in a condition that will not preclude or increase future decommissioning costs, minimizing the potential for releases to the environment and reducing the frequency of inspections, thereby reducing potential risk to workers.

Bechtel Hanford Inc. (BHI), Which is DOE-RL's Environmental Fiestoration Contractor (ERC), developed a protocol for completing this demonstration at the Hanford Site for the LSDDP. The protocol was carried out at the $\mathrm{C}$ Reactor to conduct remote gamma monitoring of both personnel and areas. The demonstration occurred at a variety of locations in the $C$ Reactor building complex from September 18 through December 1997. Additionally, beta and gamma monitoring occurred at the $\mathrm{N}$ Reactor spent fuel storage basin during dewatering in July 1998.

At C Reactor, the monitors were worn by D\&D workers and RCTs who were performing the following activities: removing equipment from the outer rod room and inner rod room and performing radiological surveys in the Ball 3X Room, the fuel storage basin, and a transfer pit associated with the basin. The inner rod room, fuel storage basin, and transfer pit have dose rates greater than $100 \mathrm{mrem} / \mathrm{hr}$. At $\mathrm{N}$ Reactor, the units were used for area monitoring at strategic locations around the spent fuel storage basin.

\section{Performance Objectives}

This technology demonstration was used to assess the following features of the improved system:

- Capabilitly of monitoring an individual's dose rate from garnma radiation and displaying the reading to the individual wearing the dosimeter, with an option for monitoring beta radiation.

- Capability of transmitting the individual's dose and the dose rate, and identifying the dosimeter from which the information was received to a remotely located monitor. The information must be transmitted by wireless means (i.e., not hard wired to the transmission device).

- Capacity to provide audible and visual indicators when an alarm set point is met or exceeded. The alarm set points must be programmable for dose and dose rate set points in both the dosimeter and the remote monitoring device.

- Notification of the remote monitoring station when contact is lost with the dosimeter, either with two-way radio or physically contacting the worker.

- Capability of providing communication from the monitoring station personnel to the individual wearing the dosimeter at a minimum. Two-way communication between the dosimeter wearer and the monitoring station individual is preferred.

- Capability of transmitting and receiving data around obstructions.

- Minimum capability of monitoring 20 devices at the same time.

- Historical recall capability for the dosimeter and the remote monitoring station.

- Ability to operate at temperatures between $-10^{\circ} \mathrm{C}$ and $50^{\circ} \mathrm{C}\left(-50^{\circ} \mathrm{F}\right.$ and $\left.122^{\circ} \mathrm{F}\right)$.

- The dosimeter shall meet or exceed requirements of ANSI N13.27-1981, American National Standard Institute Performance Requirements for Pocket-Sized Alarm Dosimeters and Alarm Rate Meters (ANSI 1981) 
- The system shall not be affected by static electricity, electrical or magnetic fields, or strong radio frequencies caused by welding machines or other devices. Known effects of intense static electricity or radio frequency interference, if any, shall be stated in advance by the manufacturer.

- The exterior case of the equipment should be constructed to facilitate decontamination.

- The system must have a data-logging capability to download dose, individual, and date and time information to a commercially available IBM or compatible personal computer with a Microsoft Windows ${ }^{2}$-based program. A computer that includes a 3.5-inch floppy diskette drive and software must be supplied with the system as part of the demonstration.

- Dosimeter shall operate with readily available batteries with a lifetime of 18 months or greater in a $10 \mathrm{mrem} / \mathrm{hr}$ field, based on a standard 40 -hour work week.

- The battery shall be capable of sounding the alarm for 10 minutes, and for eight hours after low battery indication, and shall maintain information accumulated in the memory for at least 2 hours.

\section{Demonstration Chronology}

After checking the calibration of the equipment at the Pacific Northwest National Laboratory and receiving instruction from the SAIC representative, the system was put into full operation on September 18, 1997 by onsite RCTs. An SAIC representative was present to serve in an advisory capacity. Alarm set points typically were $80 \mathrm{mrem}$ integrated dose and 100 to $500 \mathrm{mrem} / \mathrm{hr}$ dose rate.

Initially, three C Reactor D\&D workers were fitted with dosimeters. An RCT attended the base station part time. By September 24, 1997, up to $10 \mathrm{C}$ Reactor workers were using monitors simultaneously. Approximately 100 hours of monitoring was accomplished through December 1997.

At the N Reactor spent fuel storage basin, one monitor fitted with a beta probe was located at the south load-out pit adjacent to the basin. At 10 other locations, dosimeters were set for gamma monitoring, and one unit was used as a repeater to transmit all the wireless signals to the bay station. This area monitoring was performed in July 1998.

\section{Monitoring with RadStarTM WRRMS}

The improved system transmission range was assessed by keeping the base station at a fixed location outside of the $C$ Reactor area and moving the electronic dosimeters (PD-4) around the reactor building from area to area. This test indicated that the transmission was very good within $62 \mathrm{~m}(200 \mathrm{ft})$ line of sight. When the line of sight between the base station and PD-4s was obstructed by solid concrete walls or other structures with height greater

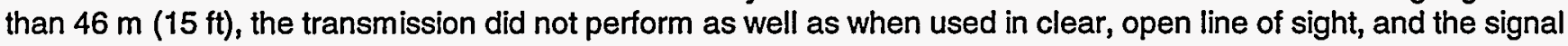
was often lost. (This could be improved by use of stationary antennae or signal repeaters.) Dosimeters were used as transmission repeaters to alleviate this problem.

At $C$ Reactor, the base station was relocated inside the northeast corner of the reactor building complex. Dosimeters were provided to four workers to verify successful transmit from various locations inside the complex. Dosimeters were sent into the outer rod room, fuel storage basin, and transfer bay, up the northeast stairwell to the top of the reactor, and into the front face work area. Transmission was maintained in these locations without the use of repeaters.

At the N Basin, the base station was behind a $61-\mathrm{cm}(2-\mathrm{ft})$-thick concrete wall at the same level that the dosimeters were set for area monitoring. Appendix $\mathrm{C}$ includes a map showing dosimeter locations. Transmission was maintained using one unit as a repeater.

\footnotetext{
${ }^{2}$ Microsoft Windows is a registered trademark of Microsoft Corporation, Redmond, Washington.
} 


\section{Monitoring with the Baseline Technology}

The baseline technology used at C Reactor is a SRD (see Figure 5). Each SRD is comprised of a small calibrated ion chamber that has a reading scale on one end, indicating the amount of dose accumulated (Figure 5). These dosimeters are commonly referred to as pocket dosimeters or pencil dosimeters. To read the scale on these dosimeters, the opposite end of the dosimeter must be directed away from the reader end to a source of light and the scale is carefully read. Using these dosimeters when work is being performed in areas that require more than one set of protective coveralls, a respirator, and extra gloves makes the reading and handling of these dosimeters more difficult. These SRDs do not directly indicate exposure

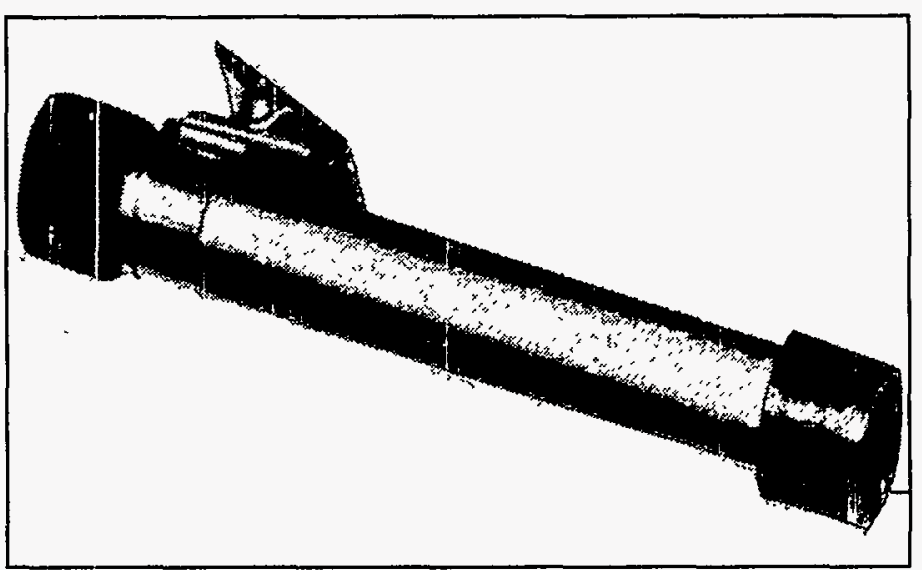

Figure 5. Quartz fiber dosimeter rate or perform any alarm functions.

At the N Basin, area monitoring was conducted and no personnel monitoring occured. The primary baseline instrument used for beta and gamma monitoring was an Eberline RO-2 direct-reading ion chamber. (Additional readings were taken with a baseline GM Xetex unit for gamma monitoring.) These instruments measure exposure rate only, (not accumulated dose), which is adequate for area monitoring, and do not record any data or signal any alarms.

\section{Dechnology Demonstration Results}

The following summarizes the successes and disappointments of the demonstration of the RadStarTM WRRMS:

\section{Successes}

- Provided supervisors the ability to observe the real-time worker dose and area exposure rate

- Resulted in one less RCT necessary to work within a contaminated work area

- Demonstrated the ability to establish data bases for individual workers

- Triggered accurate alarm set points, preventing potential over exposure, and ensuring protection of human health

- Monitored several individual employees with a different alarm set point for each individual, independent of the other workers.

- Avoided the need to bring a potentially contaminated glove or SRD into close proximity to the workers' faces as they read SRDs.

- Monitored gamma radiation, and the option to monitor beta radiation was used.

\section{Shortfalls}

- There is interference or interrupted transmission in obstructed areas or areas with thick concrete walls. However, using antennae or one or more dosimeters as repeaters usually results in adequate transmission. 


\section{Comparison to Baseline}

The calibrated PD-4s used with the WRRMS and the SRDs worn by the personnel and located in different areas within the $C$ Reactor area were demonstrated side by side to compare their responses. Results of these assessments are presented below in Table 1. Field data collected during this demonstration indicates that the improved system has better sensitivity than the baseline dosimeters, but both the improved technology and the baseline generally have similar responses in higher dose situations.

Table 1. Response sensitivity - comparison of improved to baseline technology at C Reactor

\begin{tabular}{|c|c|c|c|}
\hline Dosimeter No. & Location at C Reactor & SRD Response (mrem) & PD-4 Response (mrem) \\
\hline 28 & Fuel Storage basin & 85 & 102 \\
\hline 36 & Outer Rod Room & 0 & 0.7 \\
\hline 43 & Outer Rod Room & 0 & 0.1 \\
\hline 33 & Outer Rod Room & 0 & 0.1 \\
\hline 44 & Outer Rod Room & 0 & 0.2 \\
\hline 28 & Outer Rod Room & 0 & 0.1 \\
\hline 43 & Transfer Pit & 60 & 51.3 \\
\hline 36 & Transfer Pit & 80 & 61.4 \\
\hline 43 & Inner Rod Room & 0 & 5.0 \\
\hline 28 & Inner Rod Room & 0 & 3.5 \\
\hline 33 & Inner Rod Room & 0 & 4.4 \\
\hline 36 & Inner Rod Room & 0 & 2.1 \\
\hline 30 & Inner Rod Room & 0 & 8.0 \\
\hline
\end{tabular}

Table 2 compares and provides a comparison of the performance of the improved and baseline technologies at C Reactor:

Table 2. Comparison of performance of improved and baseline technologies at C Reactor

\begin{tabular}{|c|c|c|}
\hline Activity or Feature & $\begin{array}{l}\text { Improved Technology } \\
\text { (WRRMS) }\end{array}$ & $\begin{array}{l}\text { Baseline } \\
\text { (SRD) }\end{array}$ \\
\hline Average setup time & 20 minutes & 5 minutes \\
\hline Flexibility & No electric cord for personal dosimeter; good & Same \\
\hline Safety/ALARA & $\begin{array}{l}\text { Better sensitivity, works in real time and with alarms, less RCT } \\
\text { exposure in contaminated work areas }\end{array}$ & Acceptable \\
\hline Durability & Same & Same \\
\hline Ease of operation & Easy; requires basic computer knowledge & Easy \\
\hline Waste generation & None & None \\
\hline Utility requirements & Batteries for dosimeters, $110 \mathrm{VAC}$ for base-station computer & None \\
\hline Training & Minimal for dosimeters; several hours for computer & Minimal \\
\hline
\end{tabular}


Table 3 shows variable conditions that may affect the performance of the WRRMS. It should be noted that the number of RCTs required for any specific task at the Hanford Site depends upon the work being performed, the duration of the work, and the level of contamination in the work area. In general, for most jobs at the Hanford Site, the ability to monitor dose remotely will eliminate the need for one RCT to enter the work area.

Table 3. Summary of variable conditions

\begin{tabular}{|c|c|c|}
\hline Variable & WRRMS Technology & Baseline Technology \\
\hline Scope of Work & $\because \because \because \vdots$ & $\therefore$ \\
\hline Location of test area & C Reactor Building area and N Basin & C Reactor Building area and N Basin \\
\hline Nature of work & $\begin{array}{l}\text { Variety of D\&D activities at C Reactor; removing } \\
\text { water from } N \text { Basin }\end{array}$ & $\begin{array}{l}\text { Variety of D\&D activities at C Reactor; } \\
\text { removing water from } N \text { Basin }\end{array}$ \\
\hline Work Environment & $\therefore$ & 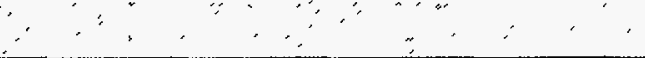 \\
\hline $\begin{array}{l}\text { Type of contamination and } \\
\text { radiation in the test areas }\end{array}$ & $\begin{array}{l}\text { Contaminated (fixed and loose) and clean } \\
\text { areas, with gamma radiation at } \mathrm{C} \text { Reactor and } \\
\text { beta/gamma radiation at } \mathrm{N} \text { Basin }\end{array}$ & $\begin{array}{l}\text { Contaminated (fixed and loose) and clean } \\
\text { areas, with gamma radiation at } \mathrm{C} \text { Reactor and } \\
\text { beta/gamma radiation at } N \text { Basin }\end{array}$ \\
\hline Work Performance . & 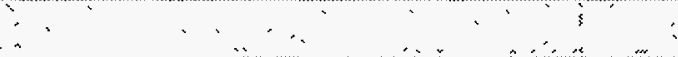 & $\therefore$ \\
\hline Technology objective & $\begin{array}{l}\text { Recording exposure rate and integrated close } \\
\text { for individuals or areas on-line (real time) }\end{array}$ & $\begin{array}{l}\text { Measures integrated personnel dose that can } \\
\text { be read after exposure }\end{array}$ \\
\hline Compliance requirements & $\begin{array}{l}\text { Compliance is necessary to meet requirements } \\
\text { for typical radiological exposure rate or dose } \\
\text { measurement }\end{array}$ & $\begin{array}{l}\text { Compliance is assumed to be that necessary } \\
\text { to meet requirements for typical dose } \\
\text { measurement }\end{array}$ \\
\hline
\end{tabular}

Data from the demonstration at $\mathrm{N}$ Basin are given in an informal report reproduced in Appendix $\mathrm{C}$. Most of the data presented in Table C-1 are gamma readings (in $\mathrm{mrem} / \mathrm{hr}$ ) from the improved system dosimeters, with the last row of the table providing the beta probe (Monitor No. XC5539) readings (in $\mathrm{mrad} / \mathrm{hr}$ ). The beta probe was mounted on Monitor No. RE1302 and monitored gamma radiation simultaneously; both gamma and beta readings were transmitted with the same transceiver. The beta probe was located at the north side of the south load-out pit (SPOP) shown on the maps in Appendix $C$. The water level in the basin where the radiation sources were varied from approximately $4.6 \mathrm{~m}$ to $9.1 \mathrm{~m}$ ( $15 \mathrm{ft}$ to $30 \mathrm{ft}$ ) vertical distance, so the beta levels recorded were relatively low, in the 11.9 to $15.1 \mathrm{mrad} / \mathrm{hr}$ range.

The handwritten data and maps provided in Appendix $C$ show $N$ Basin data taken with the baseline instruments, in some cases showing contact $/ 30-\mathrm{cm}$ pairs of readings. Note that on the ERC Radiological Survey Record forms, the gamma readings are in $\mathrm{mrem} / \mathrm{hr}$, not $\mathrm{mR} / \mathrm{hr}$ (as given on the preprinted forms). There are no side-by-side readings from the improved beta probe versus the baseline RO-2 instrument, because there was no safe access at the north side of the SLOP for using the hand-held direct-reading (not remote-reading) RO-2. The reason for using the improved beta probe at that location was that there potential existed for high exposure levels, and use of the wireless remote unit resulted in ALARA exposures. The baseline gamma readings (e.g., for July 2, 1998, at 0130 hours) show reasonable agreement with the gamma readings recorded using the improved system (e.g., for July 2, 1998, at 0110 hours).

\section{Meeting Performance Objectives}

The objectives listed earlier in this section were all met except as follows:

- Capable of monitoring 20 devices; the system demonstrated could monitor up to 16 workers simultaneously. 


\section{PERFORMANCE continued}

- Eighteen months battery life, which would apply if rechargeable batteries were furnished instead of the non-rechargeable batteries actually used. (8-hours battery life is sufficient for personal dosimeters.) An AC adapter was demonstrated for repeaters and area dosimetry.

\section{Skills/Training}

Required instruction for D\&D workers and RCTs for using the dosimeters was minimal (approximately 5 minutes of instructions). The RCT attending the base station needed basic knowledge of personal computer operations and some familiarity with the software. Five hours of on-the-job training were completed to gain this familiarity.

\section{Operational Concerns}

The main dosimeter concerns include the following:

- The length of battery life is limited to approximately 8 hours of operation as a transmitting dosimeter.

- The dosimeter has several indentations and grooves that are difficult to decontaminate, should the dosimeters become radiologically contaminated. Therefore, the dosimeter should be bagged in plastic prior to use.

The main transmission system concern is that structures may interfere with signals. However, the dosimeters (with their wireless transmission components), can be used as repeaters to transmit around interferences, or antennae can be added. 


\section{SECTION 4}

\section{TECHNOLOGY APPLICABILITY AND \\ ALTERNATIVE TECHNOLOGIES}

\section{Technology Applicability}

- This technology can be used at DOE and other public and commercial sites where workers may be performing tasks in contamination and radiation areas, including high-exposure areas.

- This technology is effective at radiologically contaminated sites where personnel are required to wear protective clothing and/or perform tasks in a remote high radiation areas with low lighting.

- The RadStar TM WRRMS can be used for both indoor and outdoor activities.

\section{Competing Technologies}

- This technology competes with other battery-powered monitoring systems (e.g., electronic dosimeters) that record, display, and store the dose or exposure rate locally on the dosimeters themselves. The competing technologies do not report data remotely in real-time; rather, data is accessed either during the task on an as-needed basis or after the personnel exit the job area. Therefore, competing technologies are not as effective at providing information for proactive decision-making regarding health and safety management. $A$ wireless remote system with real-time capability for monitoring exposure rates and recording of accumulated dose is marketed by MGP Instruments (Smyrna, Georgia). The MGP system does not have the capability of transmitting signals from the base station to the dosimeters.

- Alternative methods to the RadStar ${ }^{T M}$ system are the baseline technologies, the conventional SRD (pencil dosimeters) with the training provided to employees for proper use of such dosimeters, and direct-reading ion-chamber meters.

\section{Patents/Commercialization/Sponsors}

This technology is patented and commercially available though SAIC. 


\section{SECTION 5}

\section{COST}

\section{Methodology}

Cost elements for the improved technology and analysis of the potential for savings relative to equivalent cost elements for the baseline technology are summarized below. The objective is to assist a decision-maker, who is debating whether further investigation of the improved technology is warranted or whether to deploy the technology.

This cost analysis compares the innovative RadStar ${ }^{\top M}$ WRRMS technology (for monitoring radioactive dose and dose rate to workers by using a remote communication and recording station) to a baseline technology consisting of SRDs, which are passive dosimeters that must be monitored by RCTs when workers enter high radiation areas. Costs for the improved technology are based on remotely monitoring four workers removing asbestos and equipment in the Ball $3 X$ room of the $C$ Reactor. Costs for the baseline technology are based upon the same number of D\&D workers conducting the same removal activities, but using the pencil dosimeters and a RCT who is fully suited in the high contamination area with the workers. Activities included for cost comparison are as follows:

\section{Improyed Technology.}

-

- $\quad$ D\&D work in the Ball $3 X$ room

- Remotely monitor D\&D workers in the Ball $3 X$ room for contamination

- Use RCTs to survey and decontaminate material being removed from the work area

- Decontaminate equipment and workers leaving the contamination area.

\section{Baseline Technology}

- Set up SRDs on the D\&D workers

- D\&D work in the Ball $3 X$ room

- Monitor the D\&D workers by reading the SRDs and by having an RCT take readings in the work area

- Use RCTs to survey and decontaminate material being removed from the work area

- Decontaminate equipment and workers leaving the contamination area.

\section{Cost Analysis}

The RadStar'M WRRMS technology is available from the vendor in the forms and at the rates indicated in Table 5. All costs are based on 1997 pricing data made available by SAIC.

Table 5. Improved technology acquisition costs

\begin{tabular}{|c|c|c|}
\hline Acquisition Option & Item & $\operatorname{Cost}^{(1)}$ \\
\hline Equipment Purchase & $\begin{array}{l}\text { - PD-4 Telemetric Dosimeter (each) } \\
\text { - PDR-1 Dosimeter Reader } \\
\text { - PDX-4 Base Station Receiver } \\
\text { - PC Software }\end{array}$ & $\begin{array}{r}\$ 2,195 \\
\$ 2,295 \\
\$ 1,995 \\
\text { no charge } \\
\text { Total: } \$ 6,458\end{array}$ \\
\hline Equipment Lease (minimum 3 month lease required) & $\begin{array}{l}\text { PD-4 Telemetric Dosimeter (each) } \\
\text { - PDR-1 Dosimeter Reader } \\
\text { - PDX-4 Base Station Receiver } \\
\text { - PC Software }\end{array}$ & $\begin{array}{r}\$ 320 / \text { month } \\
\$ 320 / \text { month } \\
\$ 280 / \text { month } \\
\text { no charge } \\
\text { Total: } \$ 920 / \text { month }\end{array}$ \\
\hline
\end{tabular}




\begin{tabular}{|l|c|c|}
\hline \multicolumn{1}{|c|}{ Acquisition Option } & Hem & Cost(i) \\
\hline $\begin{array}{l}\text { Vendor Service (Daily cost includes vendor technician wages } \\
\text { and per diem. For the complete service cost, the daily } \\
\text { technician rate is added to the total equipment lease rate listed } \\
\text { above.) }\end{array}$ & $\cdot$ Vendor Technician & $\$ 750 /$ day \\
\hline
\end{tabular}

Observed unit costs for principal components of the demonstrations for both the innovative and baseline technologies are presented in Table 5.

Table 5. Summary of unit costs

\begin{tabular}{|l|c|l|c|}
\hline \multicolumn{2}{|c|}{ Improved Technology } & \multicolumn{1}{c|}{ Baseline Techinology } \\
\hline \multicolumn{1}{|c|}{ Cost Element } & Unit Cost ${ }^{\left({ }^{(1)}\right.}$ & \multicolumn{1}{c|}{ Cost Element } & Unit Cost ${ }^{(1)}$ \\
\hline $\begin{array}{l}\text { 1 Remote Dosimeter } \\
\text { (equipment costs only) }\end{array}$ & $\$ 0.90 / \mathrm{hr}$ & $\begin{array}{l}\text { 1 Pencil Dosimeter } \\
\text { (equipment costs only) }\end{array}$ & $\$ 0.10 / \mathrm{hr}$ \\
\hline $\begin{array}{l}\text { Dosimeter Reader and Base Station } \\
\text { Receiver (equipment costs only) }\end{array}$ & $\$ 1.64 / \mathrm{hr}$ & $\begin{array}{l}\text { R-03 Hand-Held Detector } \\
\text { (equipment costs only) }\end{array}$ & $\$ 0.92 / \mathrm{hr}$ \\
\hline $\begin{array}{l}\text { Remote Monitoring of Workers Using } \\
\text { the SAIC RadStarTM System }\end{array}$ & $\$ 639 /$ day & $\begin{array}{l}\text { RCT Monitoring of Workers } \\
\text { Inside the Work Area }{ }^{(3)}\end{array}$ & $\$ 851 /$ day \\
\hline
\end{tabular}

(1) Unit costs indicated are only for the equipment and activities shown and do not consider mobilization, setup, productivity losses, or demobillzation. Hourly rates for equipment are amortized rates and are calculated in accordance with Office of Management and Budget Circular A-94 using the vendor-supplied purchase price and assumptions made regarding anticipated hours of use per year and the anticlpated service life. Seo the equipment cost calculations in cost backup cata located in Appendix B.

(2) This rate is based on purchase of the RadStartM equipment and includes setting up telemetric dosimeters on four D\&D workers and remotely monitoring them with one RCT. The rate also includes one RCT monitoring outside the contamination area.

(3) This rate is based on Hanford Site ownership of the SRDs and hand-held monitoring instruments and includes setting up the SRDs on four D\&D workers and also monitoring them with one RCT working inside the contamination area. The rate also includes two RCTs monitoring outside the contamination area. 
Figure 6 is a chart displaying a comparison of costs between the improved and baseline technologies for monitoring radiation dose received by D\&D workers as they removed asbestos and disassembled equipment in the Ball $3 X$ room of the $C$ Reactor. The comparison is based on total observed costs for each technology.

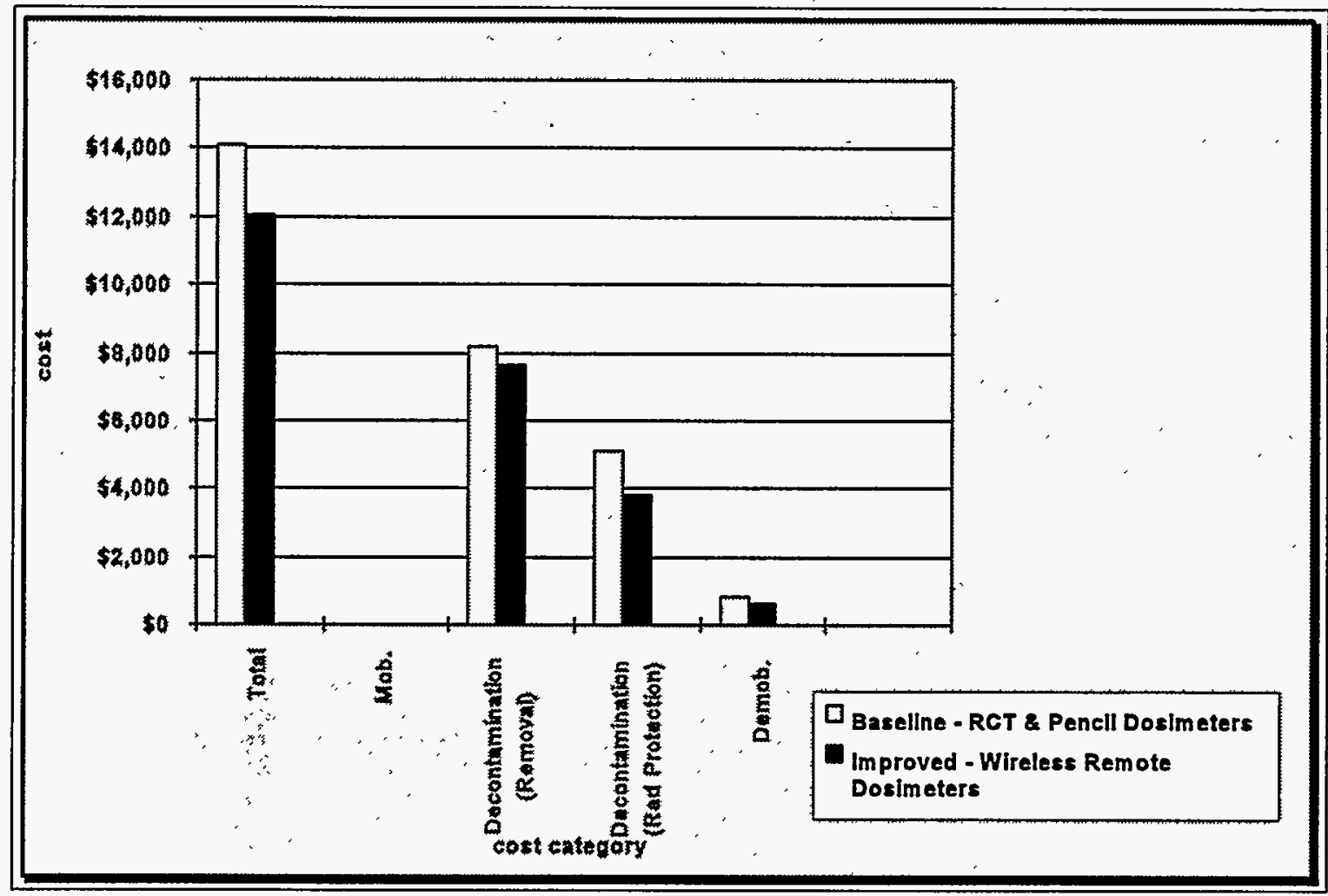

Figure 6. Costs.

\section{Cost Conclusions}

For this comparison, costs for the D\&D tasks performed in the Ball $3 X$ room are nearly identical. The primary difference in costs between the innovative and baseline technologies, as seen in Figure 6 , is due to the number of RCTs required for monitoring worker dose. Standard Hanford Site protocol for worker dose monitoring using the baseline technology is for one or more RCTs to be present in the contamination area during D\&D work. With the remote- monitoring capability of the innovative technology, it is not necessary to send an RCT in with the workers.

The number of RCTs required for any specific D\&D task at the Hanford Site depends upon the work being performed, the duration of the work, and the level of contamination in the work area. In general, for most jobs at the Hanford Site, the ability to monitor dose remotely will eliminate the need for one RCT. This not only eliminates costs for RCT wages, but also eliminates personal protective equipment costs for the RCT.

Another benefit (which is less tangible) of not having to send an RCT into the work area is in dose savings. This savings is not factored as part of the cost comparison, but is calculated at the Hanford Site as follows, based on avoiding an exposure of $0.02 \mathrm{rem} / \mathrm{hr}$ in the Ball $3 X$ room and avoiding a man-rem ranging in value up to $\$ 30,000$ :

Savings $=$ task duration $(\mathrm{hr}) \times$ number of people $\times$ area or room exposure $\times \$ 30,000$

For work in the Ball $3 \times$ room at the $C$ Reactor, using the duration given in Table $B-2$ in Appendix $B$, this is:

Savings $=6.82 \mathrm{hr} /$ day $\times 6$ days $) \times(1$ person $) \times(0.02 \mathrm{rem} / \mathrm{hr}) \times(\$ 30,000 /$ man-rem $)=\$ 24,552$ 


\section{COST}

Conversely, a cost experienced during the demonstration of the innovative technology that was not taken into consideration in the cost comparison is training. Initial training on the innovative technology took approximately 5 hours for one RCT and was conducted-by a technical representative from SAIC. As a promotional item, the manufacturer did not charge for the training. There are costs associated with the RCT's time, however. A primary reason training costs are not included in the cost comparison is that the technology is relatively easy for experienced RCTs to use, even without on site training by a manufacturer technician. Potential users of the wireless remote technology should carefully review the available manuals on the technology to determine their own need for training. Those who may purchase the technology should also check with the manufacturer for the possibility of on site training offered at no charge.

A detailed description of assumptions used to formulate the cost comparison is contained in Appendix $B$ of this report. 


\section{SECTION 6}

\section{REGULATORY AND POLICY \\ ISSUES}

\section{Regulatory Considerations}

- The RadStar ${ }^{T M}$ system is a wireless remote radiation monitoring system used for monitoring personnel dose or area exposure rate. There are no special regulatory permits required for its operation and use.

This system can be used in daily operations within the requirements of 10 CFR 20 and 10 CFR 835 , and proposed 10 CFR 834 for radiological protection of workers and the environment, and OSHA guidelines (29 CFR).

\section{Safety, Risk, Benefits, and Community Reaction}

\section{Worker Safety}

- Normal radiation protection worker safety instructions used at the facility would apply when used the improved technology is in radiologically controlled areas.

- Technology users should implement contamination control practices when used in contaminated or potentially contaminated areas.

- Normal electrical grounding requirements should be met for recharging the batteries using the system battery charger; 115 volts-alternaing current (VAC) power outlets should be used.

- Normal worker safety precautions and practices prescribed by OSHA for operation of equipment should be followed.

\section{Community Safety}

- It is not anticipated that implementation of the WRRMS would present any adverse impacts to community safety or to the environment.

\section{Environmental Impact}

- There is no adverse impact on the environment through implementation of this technology.

\section{Socioeconomic Impacts, and Community Perception}

- Implementation of this technology is not anticipated to result in any adverse socioeconomic impacts. As ALARA and worker safety is improved through the use of this technology, the community perception of the technology's use should be positive. 


\section{LESSONS LEARNED}

\section{Implementation}

- There are no specific implementation considerations except work force attitude toward acceptance of new systems.

- The WRRMS technology can be used for contaminated interior and exterior areas.

- The WRRMS is very well suited for monitoring workers in areas with high ambient temperatures and/or when personal protective clothing or respirators must be worn.

WRRMS does not produce secondary waste.

\section{Technology Limitations/Needs for Future Development}

- The transmission signal has some limitations and should be tested when being used in areas with obstructions and thick concrete walls.

- $\quad$ Except for the use of Yagi antennas to increase radio frequency signal strength and thereby prevent devoting PD-4 dosimeters as repeaters in areas with obstructions, the demonstration indicated no need to modify features of the WRRMS.

- When a dosimeter is used with alternating-current power, the dosimeter must be manually cycled to reestablish communication with the base station in the everit of a power outage or inadvertent unplugging.

\section{Technology Selection Considerations}

- The technology is suitable for DOE nuclear facility D\&D sites or any other sites involving D\&D or remediation activities in radiologically contaminated areas, in areas where personal protective clothing is required, and where high radiation exposure levels exist.

- The technology monitors individual personnel dose or an area exposure rate in real time.

- The technology inherently reduces the potential for over-exposure situations (on-line/real-time monitoring improves ALARA practice when used in high-radiation locations). 


\section{APPENDIX A}

\section{REFERENCES}

10 CFR 835, "Standards for Protection Against Radiation," Code of Federal Regulations, as amended.

Proposed 10 CFR 834, "Environmental Radiation Protection," Code of Federal Regulations, as amended.

10 CFR 20, "Occupational Radiation Protection," Code of Federal Regulations, as amended.

29 CFR 1910, "Occupational Safety and Health Standards," Code of Federal Regulations, as amended.

29 CFR 1926, "Safety and Health Regulations for Construction," Code of Federal Regulations, as amended.

Guidelines for Producing Commercial Nuclear Power Plant Decommissioning Cost Estimates, AIF/NESP-036.

OMB Circular No. A-94.

USACE, 1996, Hazardous, Toxic Radioactive Waste Remedial Action Work Breakdown Structure and Data Dictionary.

ANSI, 1981, American National Standards Institute Perfomance Requirements for Pocket-Sized Alarrm Dosimeters and Alarm Rate Meters, ANSI N13.27, American National Standards Institute, New York, New York. 


\section{APPENDIX B}

\section{COST SUMMARY}

\section{Technology Cost Comparison}

This appendix contains definitions of cost elements, descriptions of assumptions and computations of unit costs that are used in the cost analysis.

The selected basic activities being analyzed come from the Hazardous, Toxic, Radioactive Waste Remedial Action Work Breakdown Structure and Data Dictionary (HTRW RA WBS) (USACE 1996). The HTRW RA WBS, developed by an interagency group, is used in this analysis to provide consistency with the established national standards.

Some costs are omitted from this analysis for ease of understanding and facilitating comparison with costs for the individual site. The overhead and general and administrative (G\&A) markup costs for the site contractor managing the demonstration are omitted from this analysis. Overhead and G\&A rates for each DOE site vary in magnitude and in the way they are applied. Decision-makers seeking site-specific costs can apply their site's rates to this analysis without having to first back out the rates used at the Hanford site.

The following assumptions were used as the basis of the cost analysis for the improved system:

- Oversight engineering, quality assurance, and administrative costs for the demonstration are not included. These are normally covered by another cost element, generally as an undistributed cost.

- A procurement cost of $7.5 \%$ was applied to all purchased equipment costs so that the costs of administering the purchase are accounted for (this cost is included in the hourly rate).

- The equipment hourly rates for the improved technology (government's ownership option) are based on general guidance contained in Office of Management and Budget (OMB) Circular No. A-94, Cost Effectiveness Analysis (October 29, 1992).

- The standard labor rates established by the Hanford Site for estimating D\&D work are used in this analysis for the portions of the work performed by local crafts.

\section{Improved Technology - RadStarTM WRRMS}

Amortized equipment costs are detailed in notes to the tables in this appendix.

\section{MOBILIZATION (WBS 331.01)}

Pre-Read Survey Equipment: This cost element includes time for an RCT to survey the wireless remote dosimeters before they are placed on the workers who are entering the contamination area. The activity is performed once at the beginning of the 6-day work effort.

\section{DECONTAMINATION (WBS 331.17)}

D\&D Work in the Ball 3X Room: This cost element is based on a crew of four D\&D workers removing asbestos and equipment in the Ball $3 X$ Room of the $C$ Reactor over a 6-day time period. The amount of time the crew spent each day on removal activities is based on an 8-hour day less time for donning and doffing personal protective equipment, time to set up the remote dosimeters, and productivity loss as described below. The activity is measured as number of hours per day of D\&D work. 
Productivity Loss: For this cost comparison, productivity loss is measured as the number of productive hours lost per day of $D \& D$ work and is calculated by multiplying a productivity loss factor by the number of hours spent doing D\&D work. The productivity loss factor is calculated in accordance with AIF/NESP-036, Guidelines for Producing Commercial Nuclear Power Plant Decommissioning Cost Estimates. Values shown below for radiological ALARA and work breaks are taken from this guidance. The height factor shown below is modified downward from the standard range of values published in the guidelines. This is due to the fact that no scaffolding was used and workers had to reach above their heads only an estimated $15 \%$ of the time they spent doing demolition work.

\begin{tabular}{lr} 
Base: & 1.00 \\
+Height Factor & 0.02 \\
+Rad/ALARA & 0.20 \\
+Work Breaks & 0.10 \\
\hline Total: & 1.32
\end{tabular}

Don PPE: This cost item includes time for each of four D\&D workers and two RCTs to fully suit-up in personal protective equipment for the duration of the work effort as well as material costs for the personal protective equipment. Material costs for daily PPE for one D\&D worker at the Hanford Site are shown in the table below:

\begin{tabular}{|l|r|r|r|}
\hline \multicolumn{1}{|c|}{ Equipment } & $\begin{array}{c}\text { Cost Each } \\
\text { Time Used (\$) }\end{array}$ & $\begin{array}{c}\text { No. Used } \\
\text { Per Day }\end{array}$ & $\begin{array}{c}\text { Cost Per } \\
\text { Day (\$) }\end{array}$ \\
\hline Booties & 0.62 & $2 \mathrm{pr}$ & 1.24 \\
Coverall & 5.00 & $2 \mathrm{ea}$ & 10.00 \\
Double Coverall (5\% of the time) & & & 0.56 \\
Hood & 2.00 & $2 \mathrm{ea}$ & 4.00 \\
Gloves (inner) & 0.14 & $2 \mathrm{pr}$ & .28 \\
Gloves (outer) & 1.30 & $2 \mathrm{pr}$ & 2.60 \\
Gloves (liner) & 0.29 & $2 \mathrm{pr}$ & .58 \\
Rubber Overshoe & 1.38 & $2 \mathrm{pr}$ & 2.76 \\
\hline \multicolumn{2}{|r}{} \\
\hline
\end{tabular}

Set Up Remote Monitors on Workers: This cost includes time to set up the remote monitoring system, including placing remote dosimeters on each worker. The cost item also includes time to ensure that each dosimeter monitoring a worker in the contamination zone is broadcasting and receiving correctly and that the receiving base station is also receiving and relaying data correctly to the computer. The activity is measured as number of hours per day of D\&D work.

Remote Monitoring of Workers Inside the Contamination Area: This activity involves one RCT monitoring the information being received at the computer from each remote dosimeter. This same RCT will also periodically step away from monitoring worker dosimeters to assist another RCT in surveying and decontaminating waste coming out of the contamination area (Ball $3 X$ room). Time for the activity is set up to match the daily number of work hours the D\&D crew spends doing demolition work in the in the Ball $3 X$ room.

RCT Monitoring Outside the Contaminated Area: This activity involves one RCT receiving, surveying and decontaminating waste coming out of the Ball 3X Room. The RCT monitors exiting material for contamination with an Eberline E-600 hand-held detector. As with remote monitoring, the time for this activity is setup to match the time D\&D workers spend doing demolition work in the Ball $3 X$ room. 


\section{DEMOBILIZATION (WBS 331.21)}

Decontaminating Equipment \& Workers Exiting the Work Area: This cost item includes checking for contamination on workers and their tools leaving the work area and then decontaminating (if required). This activity is measured as a number of hours per day of D\&D work.

Doff PPE: This cost item includes the time it takes for the four decontamination workers doing the demolition work and the two RCTs monitoring their work to remove and dispose of their protective clothing. An allowance for disposal of the used personal protective equipment is also included. This activity is measured as a number of hours per day of D\&D work.

\section{Cost Analysis}

The following cost table calculates total costs to monitor four decontamination workers equipped with remote transceiving dosimeters, conducting a 6-day effort to remove asbestos and equipment from the Ball $3 X$ room at the $\mathrm{C}$ Reactor. Costs for the actual removal work conducted by Hanford Site decontamination workers are also included in the table, however costs associated with special measures taken for asbestos abatement and costs associated with disposing of other material and equipment removed from the Ball $3 \times$ room are not included. These costs are excluded because of their irrelevance to a radiation dose monitoring technology.

Costs presented in the table are based on purchase of the RadStar ${ }^{\mathrm{TM}}$ wireless remote monitoring equipment from the vendor (in this case, the manufacturer). Equipment costs are formulated as hourly rates using a standardized method to amortize costs. Notes to the table reference the methodology followed when calculating the hourly rates and list the assumptions made for cost equation variables. Actual calculations of the equipment hourly rates are contained in the cost backup data which is part of the project file.

The reader will note that costs for the removal work in the Ball $3 X$ room are nearly identical for both the improved and baseline technologies. (There is a small cost difference present in donning and doffing of personal protective equipment due to requirement to have an additional RCT present for the baseline technology.) Removal costs are included in the comparison between the improved and baseline technologies in order to establish a cost relationship between radiation dose monitoring and total costs for a typical D\&D work effort.

\section{Baseline Technology - Pencil Dosimeters and RCT Monitoring}

\section{MOBILIZATION (WBS 331.01)}

Pre-Read Survey Equipment: This cost element includes time for an RCT to survey the pencil dosimeters before they are placed on the workers who are entering the contamination area. The activity is performed once at the beginning of the 6-day work effort.

\section{DECONTAMINATION (WBS 331.17)}

D\&D Work in the Ball 3X Room: This cost element is based on a crew of four D\&D workers removing asbestos and equipment in the Ball $3 \times$ Room of the $C$ Reactor over a 6-day time period. The amount of time the crew spent each day on removal activities is based on an 8-hour day less time for donning and doffing personal protective equipment, time to set up the remote dosimeters, and productivity loss as described below. The activity is measured as number of hours per day of D\&D work. 
Table B-1. Improved/innovative technology cost summary (wireless remote monitoring)

\begin{tabular}{|c|c|c|c|c|c|c|c|c|c|}
\hline \multirow{3}{*}{$\begin{array}{l}\text { Work Breakdown } \\
\text { Structure (WBS) }\end{array}$} & \multicolumn{4}{|c|}{ Unit Cost (UC) } & \multirow{3}{*}{$\begin{array}{l}\text { Total } \\
\text { Qty. } \\
\text { (TQ) }\end{array}$} & \multirow{3}{*}{$\begin{array}{c}\text { Unit of } \\
\text { Measure }\end{array}$} & \multirow{3}{*}{\begin{tabular}{|c|} 
Total Cost \\
(TC-see \\
note 1) \\
\end{tabular}} & \multirow[b]{3}{*}{ Crew } & \multirow[b]{3}{*}{ Comments } \\
\hline & Labor & Equipment & \multirow{2}{*}{$\begin{array}{l}\text { Other } \\
\text { Rate }\end{array}$} & \multirow{2}{*}{\begin{tabular}{|c|} 
Total \\
UC \\
\end{tabular}} & & & & & \\
\hline & Hour Rate & Hour Rate & & & & & & & \\
\hline \multicolumn{6}{|c|}{ MOBILIZATION (mob)-WBS 331:01 } & Subtotal: & $\$ 8.56$ & & \\
\hline $\begin{array}{l}\text { Pre-Rad Survey } \\
\text { Equipment }\end{array}$ & $0.17 \$ 49.45$ & $0.17 \$ 0.92$ & & $\$ 9$ & 1 & each & $\$ 8.56$ & $1 \mathrm{RCT}$ & $\begin{array}{l}\text { RCT equipment is pre-surveyed only once at } \\
\text { the beginning of the } 6 \text {-day work effort }\end{array}$ \\
\hline \multicolumn{6}{|c|}{ DECONTAMINATION (deCOn)-WBS 331,17 } & Subtotal: & $\$ 11,437.17$ & & \\
\hline $\begin{array}{l}\text { D\&D Work in the Ball } 3 x \\
\text { Room }\end{array}$ & $5.14 \$ 127.88$ & & & $\$ 657$ & 6 & day & $\$ 3,943.82$ & 4 decon. techs & \\
\hline Productivity Loss & $1.94 \$ 226.78$ & & & $\$ 440$ & 6 & day & $\$ 2,638.63$ & $\begin{array}{l}4 \text { decon. techs; } \\
\text { 2 RCTs }\end{array}$ & \\
\hline Don PPE & $0.17 \$ 226.78$ & & $\$ 132.00$ & $\$ 171$ & 6 & day & $\$ 1,023.32$ & $\begin{array}{l}4 \text { decon. techs; } \\
2 \text { RCTs }\end{array}$ & $\begin{array}{l}\text { Other rate consists of material costs for } 6 \\
\text { sets of PPE }\end{array}$ \\
\hline \multicolumn{10}{|l|}{ Radiation Monitoring } \\
\hline $\begin{array}{l}\text { Set Up Remote } \\
\text { Monitors on Workers }\end{array}$ & $0.33 \$ 226.78$ & $\begin{array}{ll}.33 & \$ 5.22 \\
\end{array}$ & & $\$ 77$ & 6 & day & $\$ 459.36$ & 4 decon. techs; 1 RCT & $\begin{array}{l}\text { Total time is based on } 5 \text { minutes each day } \\
\text { for four decon techs (1 RCT Idle) }\end{array}$ \\
\hline $\begin{array}{l}\text { Remote Monitoring of } \\
\text { Workers Inside the } \\
\text { Contaminated Area }\end{array}$ & $5.14 \$ 49.45$ & $5.14 \$ \$ 5.22$ & & $\$ 281$ & 6 & day & $\$ 1,686.02$ & RCT & \\
\hline $\begin{array}{l}\text { RCT Monitoring } \\
\text { Outside the } \\
\text { Contaminated Area }\end{array}$ & $\begin{array}{ll}5.14 & \$ 49.45\end{array}$ & $5.14 \quad \$ 5.22$ & & $\$ 281$ & 6 & day & $\$ 1,686.02$ & 1 RCT & \\
\hline \multicolumn{3}{|c|}{ DEMOBILIZATION (demob)-WBS 331,21} & & & & Subtotal: & $\$ 632,87$ & & - \\
\hline $\begin{array}{l}\text { Decontaminate Equipment } \\
\text { and Workers Exiting the } \\
\text { Work Area }\end{array}$ & $0.25 \$ 226.78$ & $0.25 \$ \$ 0.92$ & & $\$ 57$ & 6 & day & $\$ 341.55$ & $\begin{array}{l}4 \text { decon. techs; } 2 \\
\text { RCTs }\end{array}$ & $\begin{array}{l}\text { Activity performed at the end of every work } \\
\text { day }\end{array}$ \\
\hline Doff PPE & $0.17 \$ 226.78$ & & $\$ 10.00$ & $\$ 49$ & 6 & day & $\$ 291.32$ & $\begin{array}{l}4 \text { decon. techs; } 2 \\
\text { RCTs }\end{array}$ & Includes $\$ 10.00 /$ day for PPE disposal \\
\hline
\end{tabular}

Notes:

(1) TC=UC $\times T Q$ (where TC=total cost; UC=unit cost, and TQ=total quantity).

(2) The equipment rate of $\$ 5.22 / \mathrm{hr}$ includes $\$ 3.58 / \mathrm{hr}$ for for remote dosimeters, $\$ 0.86 \mathrm{hr}$ for the dosimeter reader, and $\$ 0.78 / \mathrm{hr}$ for the base stallon recelver. Equipment rates are calculated in accordance with OMB Circular A-94 using the vendor-supplied purchase price plus a 7.5\% Hanford Site procurement cost, an anticipated usage of $500 \mathrm{hrs} / \mathrm{yr}$, an anticipated 10-year service life for all components, recalibration and maintenance costs for the remote dosimeters, and a discount rate of $5.8 \%$ for all components.

(3) Crew rates are based on $\$ 49.50 / \mathrm{hr}$ for a BHI RCT and $\$ 31.97 \mathrm{mr}$ for a BHI decon. technician. Hourly rates are based on direct rates for the Hanford Site and include base wage, fringe, TMA, and area overhead, but exclude BHI G\&A and overhead.

(4) The Hanford Site indirect expense rates for common support and materials are also omitted from this analysis. Overhead rates for each DOE site vary in magnitude and in the way they are applied. Decision makers seeking site specific costs can apply their site's rates to this analysis without having to first back out the Hanford Site's rates. This omission does not sacrifice the cost savings accuracy because overhead is applied to both the improved and baseline technology costs. Engineering, quality assurance, administrattve costs, and taxes on services and materials are also omitted from this analysis for the same reasons indicated for the overhead rates. The standard labor rates established by the Hanford Site for estimating D\&D work are used in this analysis for the portions of the work performed by local crafts. Additionally, the analysis assumes an 8-hour work day and a 40-hour work week. 
Productivity Loss: For this cost comparison, productivity loss is measured as the number of productive hours lost per day of D\&D work and is calculated by multiplying a productivity loss factor by the number of hours spent doing D\&D work. The productivity loss factor is calculated in accordance with AIF/NESP-036 Guidelines for Producing Commercial Nuclear Power Plant Decommissioning Cost Estimates. Values shown below for radiological/ALARA and work breaks are taken from this guidance. The height factor shown below is modified downward from the standard range of values published in the guidelines. This is due to the fact that no scaffolding was used and workers had to reach above their heads only an estimated $15 \%$ of the time they spent performing demolition work.

\begin{tabular}{lr} 
Base: & 1.00 \\
+Height Factor & 0.02 \\
+Rad/ALARA & 0.20 \\
+Work Breaks & 0.10 \\
\cline { 2 - 2 } Total: & 1.32
\end{tabular}

Don PPE: This cost item includes time for each of four D\&D workers and RCTs to fully suit-up in personal protective clothing for the duration of the work effort as well as material costs for the PPE. Material costs for daily PPE for one D\&D worker at the Hanford Site are shown in the table below:

\begin{tabular}{|l|r|r|r|}
\hline & $\begin{array}{c}\text { Cost Each } \\
\text { Time Used (\$) }\end{array}$ & $\begin{array}{c}\text { No. Used } \\
\text { Per Day }\end{array}$ & $\begin{array}{c}\text { Cost Per } \\
\text { Day (\$) }\end{array}$ \\
\hline Booties & 0.62 & $2 \mathrm{pr}$ & 1.24 \\
Coverall & 5.00 & $2 \mathrm{ea}$ & 10.00 \\
Double Coverall (5\% of the time) & & & 0.56 \\
Hood & 2.00 & $2 \mathrm{ea}$ & 4.00 \\
Gloves (inner) & 0.14 & $2 \mathrm{pr}$ & .28 \\
Gloves (outer) & 1.30 & $2 \mathrm{pr}$ & 2.60 \\
Gloves (liner) & 0.29 & $2 \mathrm{pr}$ & .58 \\
Rubber Overshoe & 1.38 & $2 \mathrm{pr}$ & 2.76 \\
\hline \multicolumn{2}{|r}{} \\
\hline
\end{tabular}

Set Up SRDs on Workers: This cost includes time for each worker to clip on a SRD and check the dosimeter's operation. The activity is measured as number of hours per day of D\&D work.

RCT Monitoring of Workers Inside the Contamination Area: This cost element includes time for one RCT to monitor the workers inside the contamination area (Ball $3 X$ room). The RCT is present to check general dose levels using a $\mathrm{R} 03$ hand-held detector. Time for the activity is set up to match the daily number of work hours the $D \& D$ crew spends doing demolition work in the in the Ball $3 X$ room.

RCT Monitoring Outside the Contaminated Area: This activity involves two RCTs receiving, surveying, and decontaminating waste coming out of the Ball $3 \times$ Room. Exiting waste material is monitored with an Eberline E600 hand-held detector. As with RCT monitoring inside the contamination area, the time for this activity is setup to match the time D\&D workers spend doing demolition work in the Ball $3 X$ room.

\section{DEMOBILIZATION (WBS 331.21)}

Checking SRDs: This cost activity includes time for one RCT to gather each pencil dosimeter worn by a worker in the Ball $3 \times$ room at the end of each day of work and checking the dosimeters for accumulated dose. The cost also includes running an instrument sweep of each dosimeter to check for radiological contamination. The cost item is measured as number of hours spent performing the activity for each day of D\&D work. 
Decontaminating Equipment \& Workers Exiting the Work Area: This cost item includes checking for contamination on workers and their tools leaving the work area and then decontaminating (if required). This activity is measured as a number of hours per day of D\&D work.

Doff PPE: This cost item includes the time it takes for the four decontamination workers doing the demolition work and the threeRCTs monitoring their work to remove and dispose of their protective clothing. An allowance for disposal of the used PPE is also included. This activity is measured as a number of hours per day of D\&D work.

\section{Cost Analysis}

The following cost table calculates total costs to monitor four decontamination workers equipped with pencil dosimeters, conducting a 6-day effort to remove asbestos and equipment from the Ball $3 X$ room at the C Reactor. Monitoring workers using the baseline methodology requires that one RCT be present with the workers in the contamination area. Costs for the actual removal work conducted by Hanford Site decontamination workers are also included in the table, but not costs associated with special measures taken for asbestos abatement nor costs associated with disposing of other material and equipment removed from the Ball $3 \times$ room. These costs are excluded because of their irrelevance to a radiation dose technology.

Costs presented in the table are based on Hanford Site ownership of the pencil dosimeters and hand-held meters. Equipment costs are formulated as hourly rates using a standardized method to amortize costs. Notes to the table reference the methodology followed when calculating the hourly rates and list the assumptions made for cost equation variables. Actual calculations of the equipment hourly rates are contained in the cost backup data that is part of the project file.

The reader will note that costs for the removal work in the Ball $3 X$ room are nearly identical for both the improved and baseline technologies. (There is a small cost difference present in donning and doffing of PPE due to requirement to have an additional RCT present for the baseline technology.) Removal costs are included in the comparison between the improved and baseline technologies in order to establish a cost relationship between radiation dose monitoring and total costs for a typical D\&D work effort. 
Table B-2. Baseline technology cost summary (pencil dosimeter and RCT monitoring)

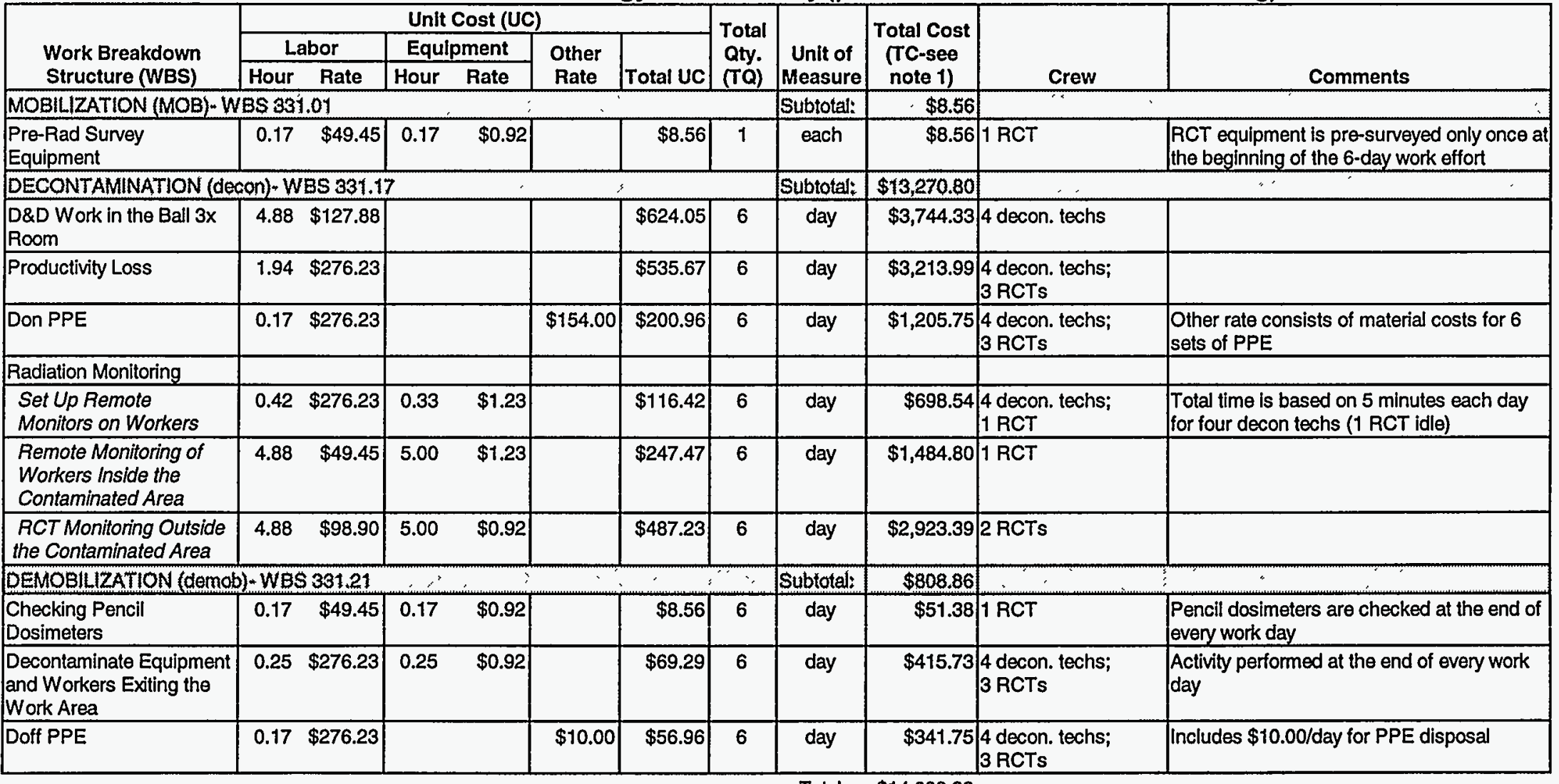

Notes:

(1) TC=UC $\times$ TQ (where TC=total cost; UC=unit cost, and TQ=total quantity)

(2) The equipment rate of $\$ 0.123 / \mathrm{hr}$ includes $\$ 0.92 / \mathrm{hr}$ for a hand-held Eberline E-600 dose/ratemeter with a HP-270 exposure rate probe and $\$ 0.31 / \mathrm{hr}$ for 7 DCA Model 862 pencil dosimeters. Equipment rates are calculated in accordance with OMB Circular A-94 using the vendor-supplied purchase price plus a $7.5 \%$ Hanford Site procurement cost, an anticipated usage of $500 \mathrm{hr} / \mathrm{yr}$, an anticipated $\mathbf{1 0 - y r}$ service life for all components, recalibration and maintenance costs for all equipment, and a discount rate of $5.8 \%$ for all components.

(3) Crew rates are based on $\$ 49.50 / \mathrm{hr}$ for a BHI RCT and $\$ 31.97 / \mathrm{hr}$ for a BHI decon. technician. Hourly rates are based on direct rates for the Hanford Site and include base wage, fringe, TMA, and area overhead, but exclude BHI G\&A and overhead.

(4) The Hanford Site indirect expense rates for common support and materials are also omitted from this analysis. Overhead rates for each DOE sites vary in magnitude and in the way they are applied. Decision makers seeking site specific costs can apply their site's rates to this analysis without having to first back out the Hanford Site's rates. This omission does not sacrifice the cost savings accuracy because overhead is applied to both the improved and baseline technology costs. Engineering, quality assurance, administrative costs, and taxes on services and materials are also omitted from this analysis for the same reasons indicated for the overhead rates. The standard labor rates established by the Hanford Site for estimating D\&D work are used in this analysis for the portions of the work performed by local crafts. Additionally, the analysis assumes an 8-hour work day and a 40-hour work week. 


\section{APPENDIX C}

\section{N-BASIN REPORT}

The appendix contains an informal report highlighting the following information:

- Use of an SAIC Model PDE-4 dosimeter with a basic gamma detector and an added beta probe.

- Use of SAIC Model PD-4 dosimeters for gamma monitoring and one unit for deployment as a radio signal repeater.

- A tabulation (Table C-1) of gamma readings from the PD-4 units, gamma readings from location "MULTI" from the PDE-4 unit, beta readings from location "BETA" from the PDE-4 unit, and water levels in the N Reactor fuel storage basin during dewatering operations.

- Radiological Survey Records with handwritten data and maps showing readings taken with baseline instruments. Some of the data are contact $/ 30-\mathrm{cm}$ pairs of readings.

Note: Gamma readings are in $\mathrm{mrem} / \mathrm{hr}$, not $\mathrm{mR} / \mathrm{hr}$ as given on the preprinted forms. 


\author{
FROM THE DESK OF: \\ S.R. Reed \\ Radiological Engineering \\ $531-0747 / X 0-23$
}

TO: $\quad$ Marve Hyman X3-41

DATE: $\quad$ August 3, 1998

\title{
SUBJECT: PD-4 WIRELESS REMOTE MONITORING USE AT N-BASIN
}

Equipment: PDE-4 with prototype beta probe, PD-4 with gamma detectors, and PD-4 repeater

Date: July 1998

Location of Base and Relay Stations: The base station was set-up in Corridor 22 of $\mathrm{N}$-Reactor approximately 50-150 feet from PD-4 Monitors. The Base Station and Monitors were on the same elevation with approximately two feet of concrete wall between them. The Monitors were placed at eleven different locations throughout the $\mathrm{N}$ Basin with one Repeater and one Beta Monitor used. The application for the Beta Monitor was not ideal for testing the performance of the monitor due to the fact that the distance from the source was too great (15-30 feet), although some background Beta radiation was observed and held constant throughout the test.

Radiation Conditions: The application for the use of the PD-4 monitors was to monitor the dose rate increases as the water was removed form the $\mathrm{N}$-Basin. The monitors were used as fixed dose rate instruments and the Base Station was set-up in a remote area where readings could be observed without making physical entry into the Radiation Area. The monitors worked very well for the testing period during water drain-down and although the dose savings were not calculated, it is certain that worker dose was saved by not entering the area and taking dose readings.

Mobilization and set-up: The set-up of the equipment took time locating the proper computer set-up and all of the necessary connection. We assembled a base unit computer attached to a rolling cart that will be used with the Base Station in the future. After the set-up, mobilization of the monitor was fairly easy. We used the AC power source for all of the monitors so battery life was not observed. One problem noticed with the AC power source was, if we had a power outage or one of the monitors was inadvertently unplugged, a person would have to make an entry to cycle the monitor so that the Base Station could reacquire the unit. All of the units that were put in use inside the Contaminated Area were wrapped in plastic prior to use. The AC power cords were not wrapped or sleeved and two of them were lost due to becoming contaminated.

Training: No formal training or OJT was performed for the RCT's using the system. A hands-on training session was performed prior to use for the RCTs that used the system. With help from personnel experienced with the system and the procedures, the PD-4 system is straightforward and easy to learn and use.

Summary: The PD-4 Wireless Remote Monitoring system worked very well for the application that it was used for. The system saved us time and dose by having a remote read-out in a clean, easily accessible area, outside of the $\mathrm{N}$-Basin. The dose rate read-out as compared to actual hand held meter reading were very close. The overall performance of the system was very good and will be beneficial in similar activities in the future. 


\section{APPENDIX C continued}

Table C-1. Radiation levels recorded with PD-4 gamma monitors and PDE-4 gamma and beta monitor

\begin{tabular}{|c|c|c|c|c|c|c|c|c|c|c|c|c|}
\hline & date-time & $7 / 1-1400$ & $7 / 1-1600$ & $7 / 1-2000$ & $7 / 1-2200$ & $7 / 1-2320$ & $7 / 2-0110$ & $7 / 6-0800$ & $7 / 6-1330$ & $7 / 6-2000$ & $7 / 7-0910$ & $7 / 7-1600$ \\
\hline location & PD-4 No. & & & & & & & & & & & \\
\hline SLOP 2 & 1628 & 5.50 & 5.00 & 5.88 & 6.43 & 5.72 & 6.59 & 5.00 & 5.05 & 5.05 & NR & NR \\
\hline SBAS 3 & 1631 & 22.00 & 22.00 & 19.40 & 18.10 & 23.10 & 16.10 & 16.50 & 16.50 & 16.50 & NR & NR \\
\hline SBAS 4 & 1635 & 47.00 & 46.00 & 49.20 & 47.80 & 49.70 & 42.50 & 45.00 & 56.20 & 52.50 & NR & 42.80 \\
\hline SBAS 5 & 1637 & 42.00 & 47.00 & 48.30 & 44.30 & 44.90 & 50.50 & 45.00 & 49.20 & 44.60 & 53.30 & 20.70 \\
\hline SBAS 6 & 1642 & 0.87 & 1.59 & 1.08 & 1.23 & 2.03 & 1.88 & 2.80 & 2.50 & 2.83 & 2.54 & 6.90 \\
\hline NBAS 7 & 1643 & 4.70 & 5.00 & 6.81 & 5.67 & 6.10 & 6.71 & 5.10 & 7.00 & 7.56 & 5.06 & 3.90 \\
\hline NBAS 8 & 1645 & 54.00 & 45.00 & 51.30 & 49.30 & 55.90 & 57.00 & 62.30 & 59.10 & 48.70 & NR & 21.50 \\
\hline NBAS 9 & 1630 & 65.00 & 57.00 & 50.60 & 55.30 & 67.50 & 56.70 & 10.10 & 59.00 & 52.90 & 51.50 & 75.50 \\
\hline CEN 10 & 1644 & 25.00 & 23.00 & 24.50 & 31.60 & 33.10 & 28.50 & 29.00 & 30.70 & 28.50 & 27.90 & 81.60 \\
\hline CEN 11 & 1639 & NR & 14.00 & 16.90 & 15.60 & 14.60 & 12.40 & 11.00 & 17.80 & 16.20 & 21.00 & NR \\
\hline MULTI & RE1302 & 5.30 & 6.00 & 4.95 & 4.63 & 5.38 & 4.99 & 5.70 & 4.70 & 5.23 & 6.50 & 3.99 \\
\hline BETA & XC5539 & 11.90 & 13.00 & 15.10 & 12.80 & 13.50 & 13.40 & 14.20 & 13.50 & 15.10 & 13.10 & 14.50 \\
\hline Water Level & & 6.60 & 6.40 & 6.20 & 5.80 & 5.80 & 5.60 & - & $\vdots$ & * & - & ? \\
\hline
\end{tabular}

"Denotes varying water levels due to using local pumps to drain over various wier gates located throughout the basin $\mathrm{NR}=$ no reading

Note: Gamma values are $\mathrm{mrem} / \mathrm{hr}$; the beta values in the bottom row are $\mathrm{mrad} / \mathrm{hr}$. 


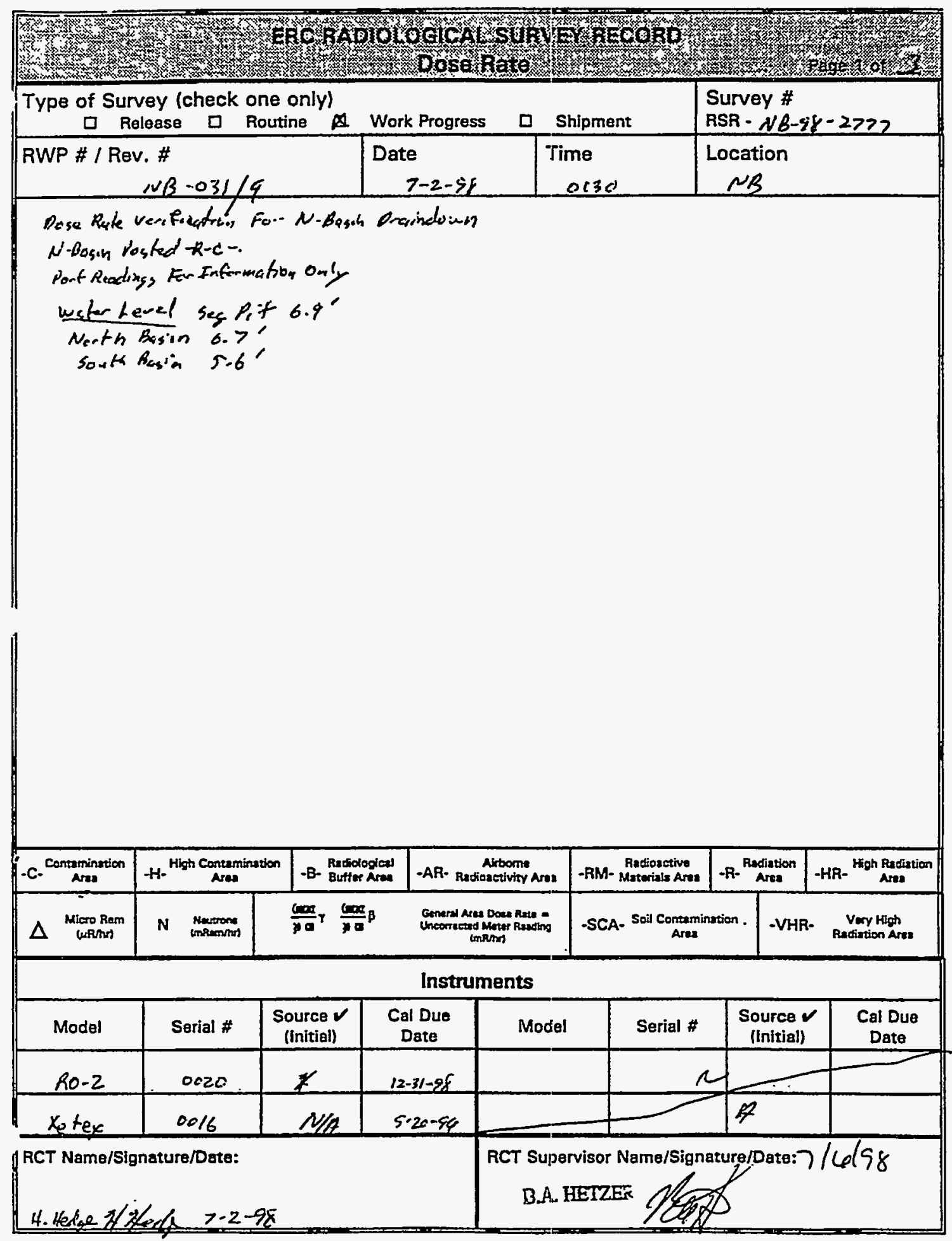

BHI-TM-R0069 (10/97)

RSR completed in accordance with BH-SH-04, Procedure 3.1. 


\begin{tabular}{|c|c|c|c|c|}
\hline & $\begin{array}{l}\text { Corrected Dose } \\
\text { Show all work. }\end{array}$ & $\begin{array}{l}\text { Ite Calculation } \\
=1 \text { unless noted. }\end{array}$ & & \\
\hline & Contact & sadings & $30 \mathrm{~cm}$ & adings \\
\hline Location & $\begin{array}{c}\beta(\mathrm{mrad} / \mathrm{hr}) \\
(\mathrm{wO} \cdot \mathrm{WC}) \times C F=D R\end{array}$ & $\begin{array}{c}Y(m R / h r) \\
W C \times C F=P R\end{array}$ & $\begin{array}{c}\beta(\mathrm{mrad} / \mathrm{hr}) \\
(\mathrm{WO}-\mathrm{WCl} \times C F=D R\end{array}$ & $\begin{array}{c}Y(\mathrm{mR} / \mathrm{hr}) \\
W C \times C F=D R\end{array}$ \\
\hline Location 1 & $\begin{array}{c}(5,5-2) 3=4 \cdot 5 \\
3+5)(4 x-2-x)\end{array}$ & 2 & & \\
\hline iocatoon 5 & NBP & 80 & & 38 \\
\hline Lesution 6 & $N \mathscr{P}$ & 6 & 1 & $\epsilon$ \\
\hline Lucgtion 7 & NBD & 6 & & 10 \\
\hline Locotion 8 & NBP & 60 & $12 / 12$ & 32 \\
\hline Locitiong & NBD & 80 & & 40 \\
\hline Lecation 10 & NBP & 80 & & 22 \\
\hline iocytion y & $(2 t-24)\}=6$ & 24 & 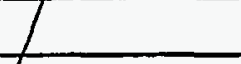 & $N / A$ \\
\hline Lucitibe 12 & NBP & 80 & 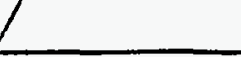 & 60 \\
\hline Port 1 Inssude & & 1800 & & \\
\hline Port 2 cinside & $N /$ & $2800 y=-2$ & & \\
\hline Port 3 Inos, dt & 74 & 24 & & \\
\hline Pooty Inside & $\angle$ & $; 200$ & & \\
\hline & & & & \\
\hline & & & & \\
\hline & & & & \\
\hline & & & & \\
\hline & & & & \\
\hline & & & & \\
\hline & & & & \\
\hline & & & & \\
\hline & & & & \\
\hline & & & & \\
\hline & & & & \\
\hline & & & & \\
\hline & & & & \\
\hline & & & & \\
\hline & & & & \\
\hline
\end{tabular}




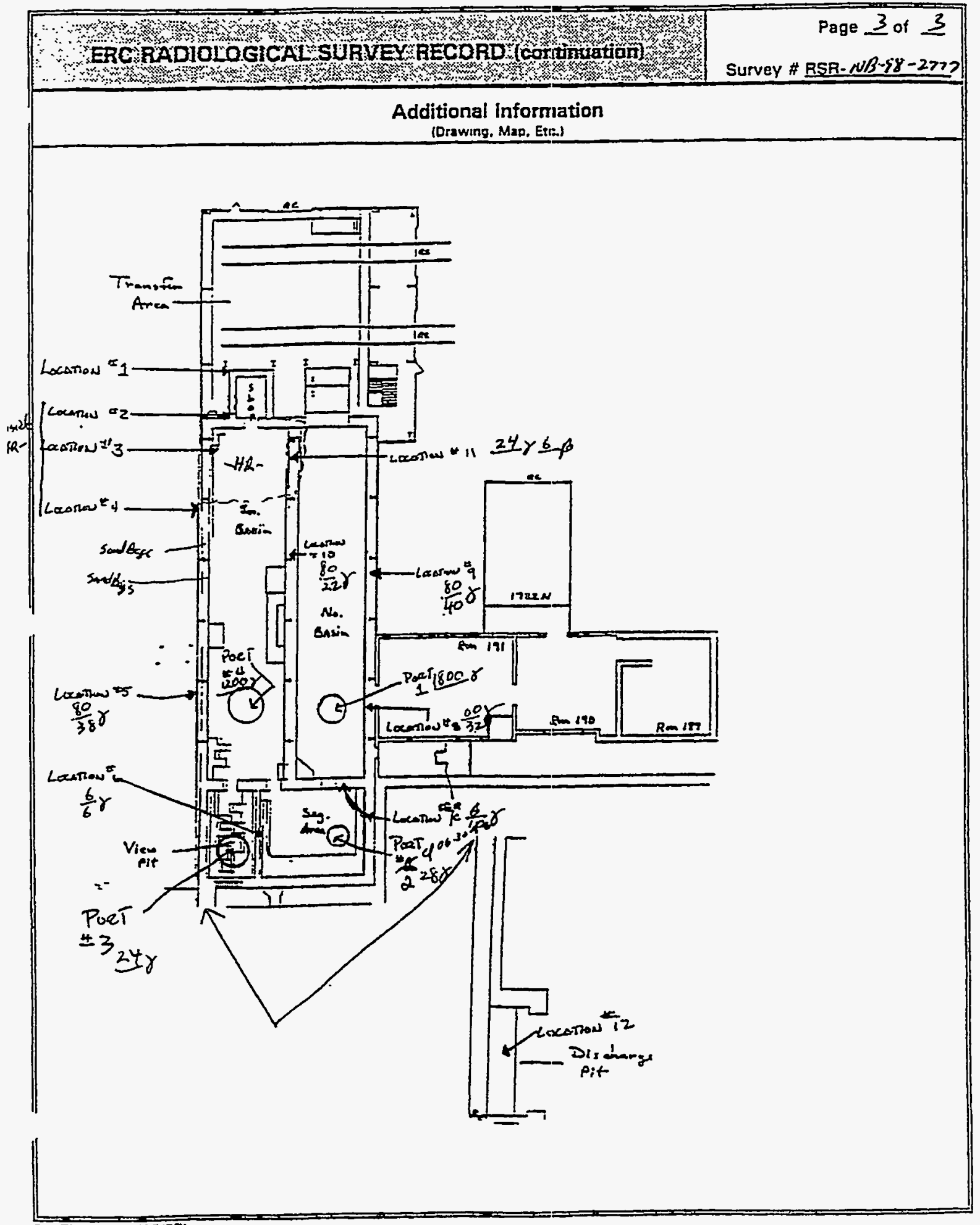

BHI-TM-ROO6c (10/97) 


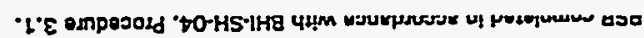

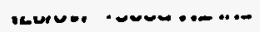

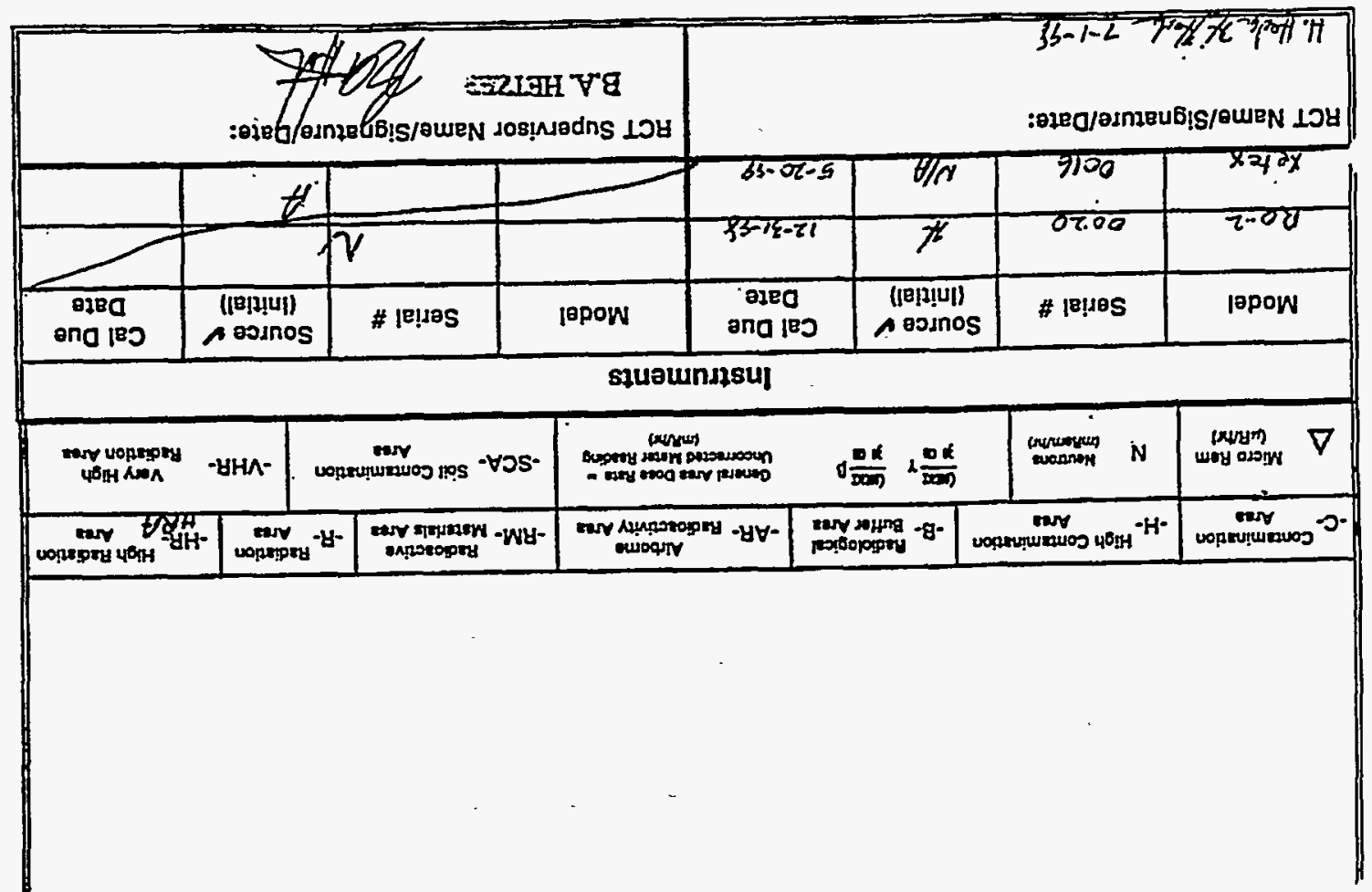

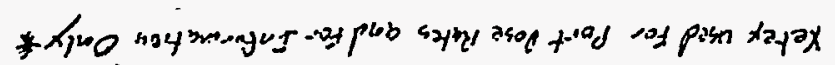

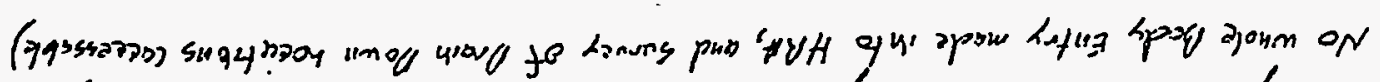

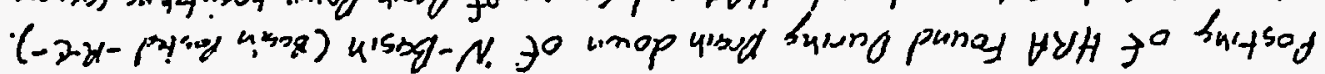

\begin{tabular}{|c|c|c|c|}
\hline $\begin{array}{c}8 N \\
\text { uo!?e507 }\end{array}$ & 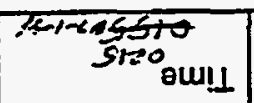 & $\begin{array}{c}35-1-2 \\
\text { oxea }\end{array}$ & 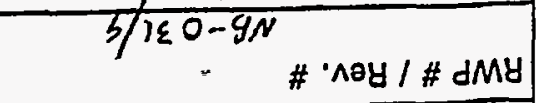 \\
\hline $\begin{array}{r}\bar{g} \varepsilon \angle Z-\delta \zeta-g n-8 S \theta \\
\# \text { Nonns }\end{array}$ & furwd!lys & Ss2J601d Y10M & 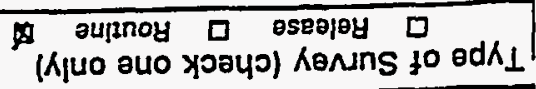 \\
\hline
\end{tabular}




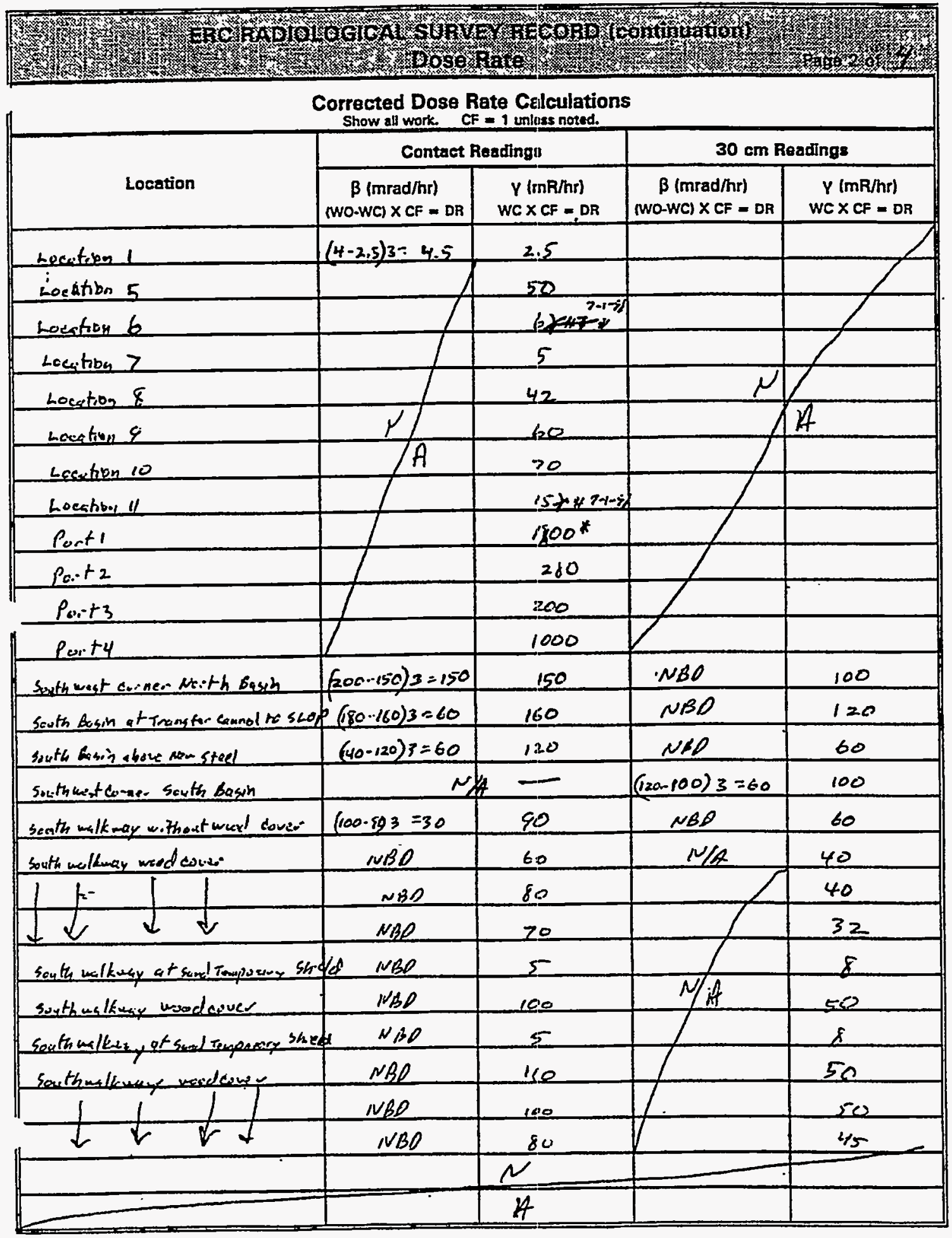




\begin{tabular}{|c|c|c|c|c|}
\hline \multirow[b]{3}{*}{ Location } & \multicolumn{4}{|c|}{$\begin{array}{l}\text { Corrected Dose Rete Calculations } \\
\text { Show all work. CF }=1 \text { unloss noted. }\end{array}$} \\
\hline & \multicolumn{2}{|c|}{ Contact Readings } & \multicolumn{2}{|c|}{$30 \mathrm{~cm}$ Readings } \\
\hline & $\begin{array}{c}\beta(\mathrm{mrad} / \mathrm{hr}) \\
(w 0-W C) \times C F=D R\end{array}$ & $\begin{array}{c}Y(m R / h r) \\
W C X C F=D R\end{array}$ & $\begin{array}{c}\beta(\mathrm{mrad} / \mathrm{hr}) \\
(\mathrm{WO}-\mathrm{WC}) \times C F=\mathrm{DR}\end{array}$ & $\begin{array}{c}Y(\mathrm{mR} / \mathrm{hr}) \\
W C \times C F=D R\end{array}$ \\
\hline Lacutien 1 & $(4-2,5) 3=4,5$ & 2.5 & & \\
\hline Locatibn 5 & & 50 & & \\
\hline Loestity 6 & & $6 x+7$ & & \\
\hline Lecution 7 & & 5 & & \\
\hline hocetion \& & & 42 & & \\
\hline Lavation \& & & 60 & & 4 \\
\hline Lescition 10 & $A$ & 70 & & \\
\hline Locahibe II & & $15 \times 47+1-i)$ & & \\
\hline Purt 1 & & $1900^{*}$ & & . \\
\hline po.t2 & & 280 & & \\
\hline$P_{0,0}+3$ & & 200 & & \\
\hline$\rho_{0.1}+4$ & & 1000 & & \\
\hline Sunthwat cornes Ne.th Bgseh & $(200 \cdot 150)_{3}=150$ & 150 & - NBO & 100 \\
\hline Seuth Basin at Trangfor Counol $x$ scos & $(180 \cdot 160) 3=60$ & 160 & NBD & 120 \\
\hline South Arsin showe now steel & $(40-120) 3=60$ & 120 & NFD & 60 \\
\hline Southwert donene- Seuth basin & $\sim N$ & - & $(120-100) 3=60$ & 100 \\
\hline Senth walkmoy without wuxl dover & $100.593=30$ & 90 & $N B D$ & 60 \\
\hline South walkmay woed dow.20 & $N B D$ & $\epsilon_{0}$ & N/S & 40 \\
\hline $1 \mathrm{k}=$ & NBD & 80 & & 40 \\
\hline$\pm \downarrow \downarrow \downarrow$ & NBP & 20 & & 32 \\
\hline South walkway at sand Touplowey Sho & NBD & 5 & & 8 \\
\hline suyth ualkury wood arver & WBP & 100 & N/if & 562 \\
\hline 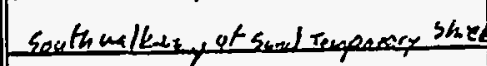 & $N B O$ & $\Sigma$ & & $\&$ \\
\hline Southusilenay, & $N B P$ & 110 & & 50 \\
\hline $1+1$ & NBO & 100 & & 50 \\
\hline $2 v \sqrt{ }$ & NBO & 80 & 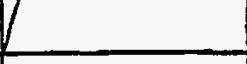 & $2 / 5$ \\
\hline & & $N$ & & \\
\hline$\cdots$ & ? & If & & \\
\hline
\end{tabular}




\section{APPENDIX C}

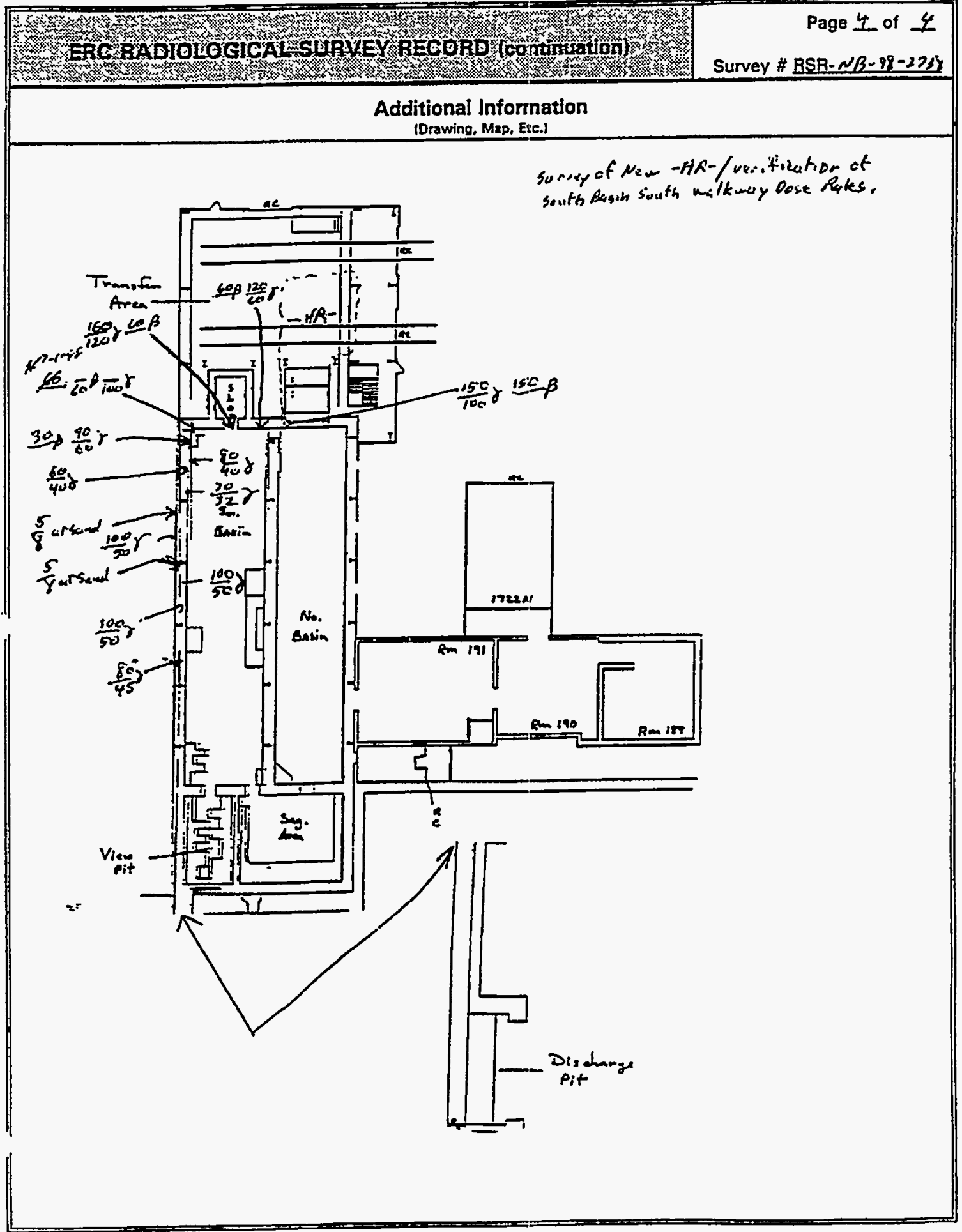


(C6)01) $9900 Y \cdot W 1-148$

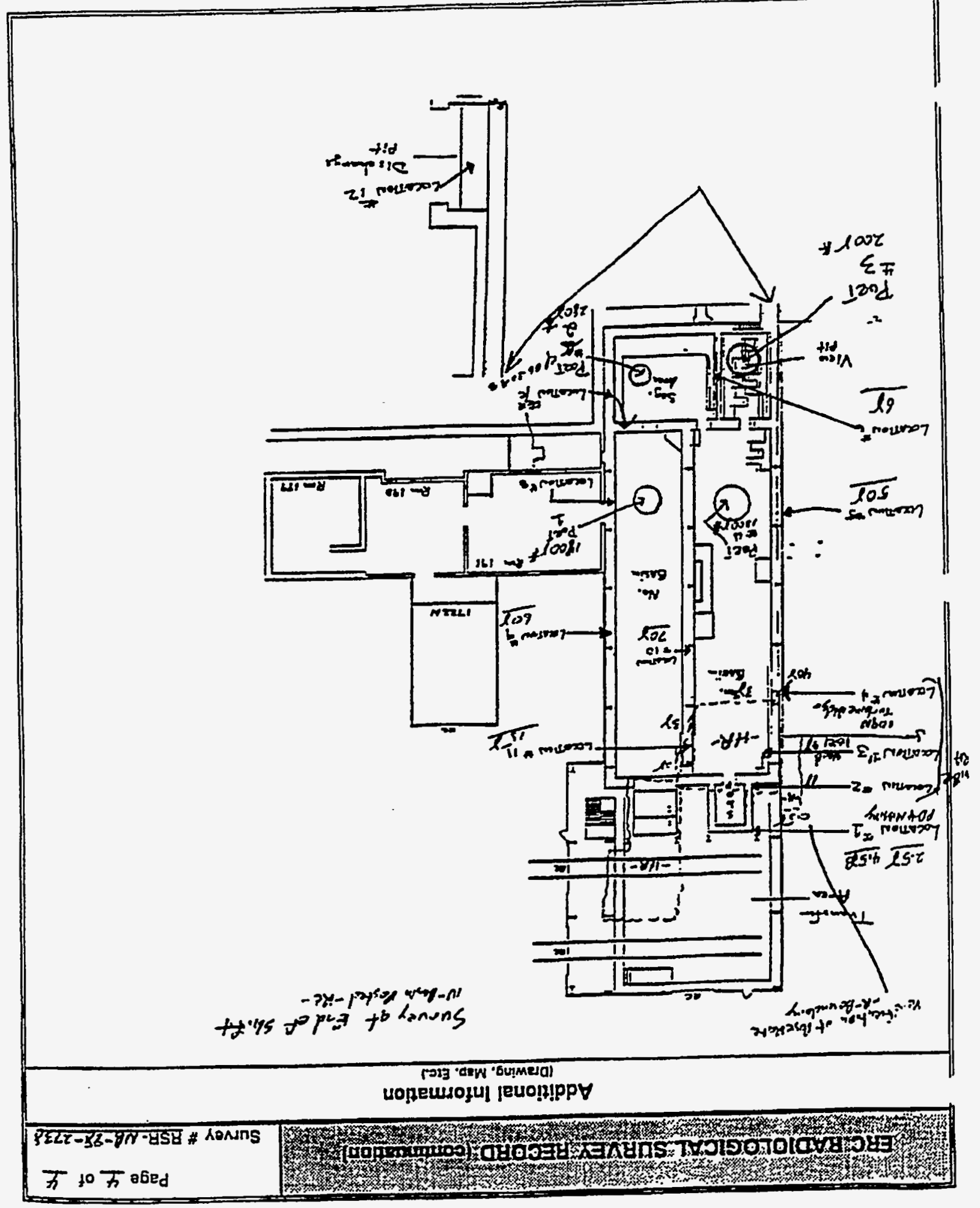




\section{APPENDIX D}

\section{ACRONYMS AND ABBREVIATIONS}

\section{Acronym/Abbreviation}

ALARA

$\mathrm{BHI}$

CFR

$D \& D$

DOE

DOE-RL

ERC

G\&A

GM

HTRW

ISS

LSDDP

$\mathrm{mR}$

$\mathrm{OMB}$

OSHA

OST

PPE

RA

RCT

$\mathrm{RL}$

SAIC

SLOP

SRD

USACE

VAC

WBS

WRRMS

\section{Description}

As Low As Reasonably Achievable

Bechtel Hanford, Inc.

Code of Federal Regulations

decontamination and decommissioning

U.S. Department of Energy

U.S. Department of Energy, Ricland Operations Office

Environmental Restoration Contractor

General and Administrative

Geiger-Mueller

Hazardous, Toxic, Radioactive Waste

Interrim Safe Storage

Large-Scale Demonstration and Deployment Project

milli-Roentgen

Office of Management and Budget

Occupational Safety and Health Administration

Offece of Science and Technology

personal protective equipment

remedial action

Radiological Control Technician

U.S. Department of Energy, Richland Operations Office

Science Applications International Corporation

South Load-Out Pit

Self-reading Dosimeter

U.S. Army Corps of Engineers

Volts, alternating current

work breakdown structure

Wireless Remote Radiation Monitoring System

Note: Additional definitions are given in Appendix B in the notes accompanying each table. 